NASA Technical Memorandum 103799

\title{
Tribological Characteristics of Silicon Carbide Whisker-Reinforced Alumina at Elevated Temperatures
}

Christopher DellaCorte

Lewis Research Center

Cleveland, Ohio

April 1991

\section{N/Sn}


TRIBOLOGICAL CHARACTERISTICS OF SILICON CARBIDE

WHISKER-REINFORCED ALUMINA AT ELEVATED TEMPERATURES

Christopher Dellacorte

National Aeronautics and Space Administration

Lewis Research Center

Cleveland, OH 44135

\section{ABSTRACT}

The enhanced fracture toughness of whisker reinforced ceramics makes them attractive candidates for sliding components of advanced heat engine. Examples include piston rings and valve stems for stirling engines and other low heat rejection devices. However, the tribological behavior of whisker reinforced ceramics is largely unknown. This is especially true for the applications described where use temperatures can vary from below ambient to well over $1000{ }^{\circ} \mathrm{C}$.

The following paper describes an experimental research program to identify the dominant wear mechanism(s) for a silicon carbide whisker reinforced alumina composite, $\mathrm{SiCW}-\mathrm{Al}_{2} \mathrm{O}_{3}$. In addition, a wear mechanism model is developed to explain and corroborate the experimental results and to provide insight for material improvement. 


\section{INTRODUCTION}

\section{A. Motivation}

A major obstacle to the application of ceramics in machinery is their inherent brittleness and tendency to fracture. This behavior is in contrast to metals which yield in a plastic manner before fracture and usually avoid catastrophic failure. One way to improve ceramics is to enhance their toughness by the addition of secondary phases, such as whiskers and particles.

These secondary phases act to inhibit and deflect crack propagation and thereby improve toughness. One example of such a material is silicon carbide whisker reinforced alumina ( $\left.\mathrm{SiCW}-\mathrm{Al}_{2} \mathrm{O}_{3}\right)$. This composite consists of an $\mathrm{Al}_{2} \mathrm{O}_{3}$ matrix with from approximately 8 to 40 vol o sic reinforcing whiskers. The composite's fracture toughness, typically 8.0 to $8.5 \mathrm{MPa} \mathrm{m}{ }^{1 / 2}$, is about twice that of unreinforced $\mathrm{Al}_{2} \mathrm{O}_{3}$ (Ref. 1). Improved fracture toughness makes this ceramic composite material attractive for use in a number of advanced applications.

Since improved fracture toughness generally means improved wear resistance, one potential area of application for this composite is high temperature sliding components in advanced heat engines such as Low Heat Rejection (LHR) diesels, stirling engines and aircraft turbine engines. Cylinder wall/piston ring sliding couples, valve stems, bushings and seals are specific examples where reinforced ceramics are being considered as tribological elements (Ref. 2).

The successful application of ceramics as triboelements depends upon a full understanding of their wear behavior especially at elevated 
temperatures. Recent tribological data on ceramics, both monolithic and reinforced types, indicate that, in the absence of lubrication, friction and wear can be quite high (Ref. 3). In order to predict and possibly improve the friction and wear characteristics of ceramics at high temperatures, the wear mechanism(s) must be understood. For studying monolithic ceramics brittle fracture theory can be used with satisfactory results. Reinforced ceramics like $\mathrm{SiCw}-\mathrm{Al}_{2} \mathrm{O}_{3}$ can behave in more complex ways.

\section{B. Background}

Researchers have studied the tribological behavior of $\mathrm{SiCW}-\mathrm{Al}_{2} \mathrm{O}_{3}$ composites. Sliney and Deadmore, for instance, examined the effect of temperature and whisker volume content of $\mathrm{SiCW}-\mathrm{Al}_{2} \mathrm{O}_{3}$ using a double block on-ring apparatus (Ref. 4). The blocks were made from SiCW-Al $\mathrm{O}_{3}$ composites and the ring material was the nickel-based superalloy Inconel 718. Their work indicated that the wear of the ceramic blocks decreased and the friction increased as the whisker content increased from 8 to 30 vol \&. They also pointed out that the transfer of lubricous metal oxides from the metal rings to the ceramic blocks has a pronounced effect on friction and wear. Namely, high metal-oxide transfer improves the tribological properties. However, the exact nature of the transfer film was unclear and complex, making specific conclusions from the data, especially regarding wear mechanisms, difficult.

In somewhat similar experiments, Fukuda, et al. studied the effect of SiC whisker content on the tribological properties of $\mathrm{SiCW}-\mathrm{Al}_{2} \mathrm{O}_{3}$ 
composites when sliding against heat treated bearing steel hardened to Hv 870 (Ref. 5). The tests were conducted at room temperature using a ceramic composite pin-on-steel disk test. Their results agree with those previously described by Sliney and Deadmore (Ref. 4). As whisker content increases, the wear of the ceramic decreases and the wear of the metallic counterface increases. They also detected significant metal oxide transfer to the ceramic, and like sliney and Deadmore, concluded that the transfer films had a significant effect on friction and wear. This is also most likely the case for monolithic and composite ceramic counterfaces.

These experiments point out that the tribological behavior of $\mathrm{SiCW}-\mathrm{Al}_{2} \mathrm{O}_{3}$ is not well understood. Furthermore, the tribological behavior is significantly complicated by the presence of transfer films. Research on $\mathrm{SiCW}-\mathrm{Al}_{2} \mathrm{O}_{3}$ composites which are tested in sliding against themselves has proven somewhat more elucidating in terms of understanding wear mechanisms and behavior.

Bohmer and Almond studied the wear resistance of self-mated $\mathrm{SiCW}-\mathrm{Al}_{2} \mathrm{O}_{3}-\mathrm{ZrO}_{2}$ using a pin-on-disk type apparatus (Ref. 6). They found that the wear resistance increased as the whisker content increased for both the pin and the disk. They attributed these results to improved toughness of the composite. Although they performed SEM analysis of the wear surfaces, they offered no explanation as to the wear mechanism(s). The most extensive research, by far, done on the wear of $\mathrm{SiCW}-\mathrm{Al}_{2} \mathrm{O}_{3}$ has been that by Yust et al. (Refs. 7 to 9). These studies have concentrated on understanding the wear processes and mechanisms of 
SiCw(20 vol \&) $-\mathrm{Al}_{2} \mathrm{O}_{3}$ sliding against itself from 20 to $800^{\circ} \mathrm{C}$. Reference 7 describes tests conducted in a nitrogen atmosphere using a pin-on-disk configuration. The atmosphere was specifically chosen to avoid tribochemical reactions so as to better understand the tribomechanical wear process. The results of this work indicated that the material wears by fracture since cracks in the wear tracks and faceted wear particles were observed. The authors did determine, in this work, that the wear of monolithic alumina was at least 2 and as much as 4 orders of magnitude greater than the 20 vol $\% \mathrm{SiCW}_{-} \mathrm{Al}_{2} \mathrm{O}_{3}$ composite. Despite acquiring appreciable wear data, the authors were unable to establish a relationship between the composite's microstructure and a wear mechanism.

Yust et al. also tested their 20 vol \& $\mathrm{SiCW}-\mathrm{Al}_{2} \mathrm{O}_{3}$ composite in an air atmosphere from 20 to $800{ }^{\circ} \mathrm{C}$ (Ref. 8). They obtained results similar to their earlier results in nitrogen except that at the highest test temperature $800^{\circ} \mathrm{C}$, an oxide layer developed on the rubbing surface and reduced wear. Auger and EDS x-ray analysis indicated that the oxide layer was predominantly a mixture of $\mathrm{Al}_{2} \mathrm{O}_{3}$ (from the matrix) and $\mathrm{SiO}_{2}$ (from oxidized SiC whiskers). TEM analysis confirmed that the wear debris was made up of very fine (10-50 $\mathrm{nm}$ diameter) particles. These particles agglomerate into larger debris "areas" on the wear tracks which macroscopically resemble plastically deformed areas. Further work by Yust, et al. indicated that subsurface dislocation movement may also 
play a role in the high temperature wear behavior although the mechanism is not exactly known (Ref. 9).

It is clear from this review that the wear behavior of $\mathrm{SiCw}-\mathrm{Al}_{2} \mathrm{O}_{3}$ composites is not well understood. This is especially true when the wear behavior is complicated by a reactive test environment and high temperatures.

For this reason, we at NASA have conducted a research program to further study the wear mechanisms of a SiCw-AI $\mathrm{O}_{3}$ composite as a function of test temperature and to determine the dominant wear mechanism(s) through the use of wear debris analysis as done by yust, et al. In this program, pin-on-disk wear tests were conducted with a self-mated $\mathrm{SiCW}-\mathrm{Al}_{2} \mathrm{O}_{3}$ composite. Then the wear surfaces were analyzed using SEM and TEM. Some of the experimental results have been reported elsewhere (Ref. 10). Based upon these analyses, the most probable dominant wear mechanism(s) were determined. Finally, to test the plausibility of the experimentally determined wear mechanism(s) an analytical model of the wear process was developed and applied.

\section{EXPERIMENTAL}

\section{A. Material}

The $\mathrm{SiCW}-\mathrm{Al}_{2} \mathrm{O}_{3}$ composite material studied contains 75 vol $8 \mathrm{Al}_{2} \mathrm{O}_{3}$ with 25 vol of SiC whiskers. Table 1 gives the material's detailed composition and manufacturer's strength/property data. Partially stabilized $\mathrm{ZrO}_{2}$ is included in the table for comparison of its bulk physical properties. 
The composite is made by hot pressing high purity $\left(>99.9 \% \mathrm{Al}_{2} \mathrm{O}_{3}\right.$ with traces of silicon and iron) alumina powder mixed with single crystal SiC whiskers. During consolidation, most of the whiskers preferentially align themselves in a plane perpendicular to the pressing direction (Ref. 11). The pins and disks tested in this study have their rubbing surfaces parallel to the whisker planes (Fig. 1).

The whiskers are single crystal SiC with lengths 10-60 $\mu \mathrm{m}$ and diameters of $\approx .75 \mu \mathrm{m}$. The matrix grain size is approximately $2 \mu \mathrm{m}$ and the material is hot pressed at approximately $1600^{\circ} \mathrm{C}$.

Figure 2 shows a TEM micrograph of the unworn or virgin material (i.e. after specimen preparation but prior to tribotesting). From this figure it can be seen that there is little residual porosity and that there is good contact between the matrix and the whiskers, i.e., there are no large voids between the whiskers and the matrix. Figure 2 shows a lengthwise cross-section of a whisker.

Wear pins, $0.48 \mathrm{~cm}$ in diameter and $2.5 \mathrm{~cm}$ long were made from the composite. Hemispheres of $2.54 \mathrm{~cm}$ radii were machined on the pin ends and were diamond polished to $a \approx .1 \mu \mathrm{m}$ rms surface finish.

The wear disks are $6.35 \mathrm{~cm}$ in diameter and $1.25 \mathrm{~cm}$ thick. The faces were diamond polished to $a \approx .1 \mu \mathrm{m}$ rms surface finish.

\section{B. Apparatus and Procedure}

The specimens were tested in a high temperature pin-on-disk tribometer (Fig. 3). With this apparatus, the pin is held in a torque tube and is loaded against a rotating disk which is mounted on a ceramic 
spindle. The spindle penetrates a SiC glowbar furnace which is capable of heating the specimens to $1200^{\circ} \mathrm{C}$. Sliding velocity during these tests was $2.7 \mathrm{~m} / \mathrm{s}(1000 \mathrm{rpm})$. The test atmosphere was ambient air with a relative humidity which ranged from 40 to $65 \%$ at $25^{\circ} \mathrm{C}$. An air atmosphere was chosen to simulate conditions expected in future applications. Reference 12 gives a detailed description of the tribometer. Prior to testing, the specimens were cleaned with pure ethyl alcohol, then rinsed deionized water and dried before being mounted in the rig. To begin a test, the pin is slowly loaded against the rotating disk and data acquisition begins.

Since initial hertzian contact stress for this material combination and geometry at the chosen test load of $26.5 \mathrm{~N}$ can be as high as $698 \mathrm{MPa}$, the first $30 \mathrm{sec}$ of sliding was at a much lower load, approximately $1 \mathrm{~N}$. This reduced the initial contact stress and allowed a wear scar to form on the pin so that at no time did the nominal contact stress exceed the compressive strength ( $\approx 500 \mathrm{MPa}$ ) of the material which may have caused cracking due to overloading. The final test load, after the brief $(\approx 30 \mathrm{sec})$ run-in at $1 \mathrm{~N}$ was $26.5 \mathrm{~N}$.

The tests were typically run for one hour for a total sliding distance of $9.7 \mathrm{~km}$. The specimens were then unloaded and the furnace was turned off and allowed to cool. The specimens were then removed from the rig to make wear measurements and to analyze the wear surfaces. The pin wear measurements were made by using optical microscopy to measure the wear scar diameter and then calculate the wear volume. Disk 
wear was measured using stylus surface profilometry of the wear track to get an average track cross-section area. The disk wear volume was then calculated by multiplying the average cross-section area by the average track diameter.

To investigate the wear mechanisms of the $\mathrm{SiCW}-\mathrm{Al}_{2} \mathrm{O}_{3}$ ceramic composite, samples of the pin wear surfaces were prepared and analyzed using both SEM and TEM techniques. For the SEM, the pin samples were coated with carbon to prevent charging and then analyzed. For the TEM, thin foils were prepared from the pin wear scars themselves by slicing the worn tip from the pin then ion mill thinning the foil from the unworn side until a hole was created in the center of the wear scar. Due to the tediousness of fabricating the TEM samples, only pin wear scars from the room temperature tests and the highest temperature tests, $1200{ }^{\circ} \mathrm{C}$, were examined. Standard TEM procedures were then used to examine the pin wear scar. Disk surface specimens were not prepared due to geometry complications which made it too difficult to prepare thin foils. Also because the pin surface is under continuous sliding it suffers more frictional heating and severe wear conditions than the disk and may provide more information regarding wear mechanisms than the disk surface.

\section{RESULTS \& DISCUSSION}

\section{A. Friction and Wear}

The friction and wear data (for both the pin and the disk) are given in Table 2 and plotted as a function of temperature in Figs. 4 
to 6. The data indicate that only the pin wear increases as the test temperature increases. Both the disk wear factor (defined as the wear volume divided by both the sliding distance and the test load) and the friction coefficient, remain relatively constant as the test temperature is increased from 25 to $120{ }^{\circ} \mathrm{C}$. The observation that the disk wear rate is relatively constant, compared to the pin wear rate which increases with temperature, is probably due to the higher pin surface temperatures induced by frictional heating as previously described. In general, average friction coefficients for the $\mathrm{SiCW}-\mathrm{Al}_{2} \mathrm{O}_{3}$ composite sliding against itself vary from a low of 0.58 to a high of 0.72 in the range of 25 to $1200{ }^{\circ} \mathrm{C}$. Average disk wear factors for the alumina composites tested here are in the range of 4 to $9 \times 10^{-7} \mathrm{~mm}^{3} / \mathrm{N}-\mathrm{m}$. Average pin wear factors show an increase with temperature from $2 \times 10^{-7}$ at $25^{\circ} \mathrm{C}$ to $12 \times 10^{-7}$ at $1200^{\circ} \mathrm{C}$. The average pin wear factor at $600{ }^{\circ} \mathrm{C}$ is highest, $15 \times 10^{-7} \mathrm{~mm}^{3} / \mathrm{N}-\mathrm{m}$. This may represent normal wear data scatter, however, since only two specimens were tested at this temperature whereas usually three or more specimen sets were available to be tested at the other test temperatures. Although the friction coefficients are high, the wear is relatively low when compared to steel sliding against steel or monolithic alumina sliding against itself under similar conditions at room temperature which have wear factors in the range of $10^{-3}$ to $10^{-4} \mathrm{~mm}^{3} / \mathrm{N}-\mathrm{m}$ (Refs. 13 and 7 ). 


\section{B. Electron Microscopy}

1. Room Temperature Behavior. - SEM analysis of the specimens from the room temperature tests indicate that the wear debris outside of the pin wear scar was predominantly short broken SiC fibers and $\mathrm{Al}_{2} \mathrm{O}_{3}$ matrix particles. Also present are large areas of compacted fine particles which at lower magnification look like plastically deformed areas (Fig. 7). In general, the room temperature wear surface indicates that the wear mode is primarily brittle fracture of both the matrix and the whiskers.

TEM analyses of the room temperature pin wear scar showed evidence of brittle fracture, individual wear particles and many cracks. No evidence of plastic behavior (dislocations) was seen. Figures $8(a)$ and (b) show typical TEM photomicrographs. These micrographs suggest that, under these test conditions, at room temperatures the wear mode is conventional, i.e., generalized brittle fracture and subsequent removal of material.

2. High Temperature Behavior. - SEM analyses of the pin wear surface and wear debris from the elevated temperature tests indicate a radically different wear mode. At $600{ }^{\circ} \mathrm{C}$, the pin wear scar shows evidence of whisker pullout. This can be seen as empty whisker pockets or troughs on the pin wear scar (Fig. 9). Also detected at elevated temperatures, were occasional wear debris particles that were in the form of wear rolls (Fig. 10). These rolls are probably the remnants of

a glassy $\mathrm{Al}_{2} \mathrm{O}_{3} / \mathrm{SiO}_{2}$ surface layer which forms during sliding as the 
oxidation product of the SiC whiskers and the $\mathrm{Al}_{2} \mathrm{O}_{3}$ matrix. As wear takes place, this glassy layer debonds and is rolled upon itself or possibly around pulled out whiskers, in the case of larger diameter rolls, to form the needle-like roll debris. This type of behavior with ceramics has been observed by other authors (Ref. 14).

At $1200{ }^{\circ} \mathrm{C}$, large areas of long, unbroken whiskers, many as long as in the virgin material and devoid of $\mathrm{Al}_{2} \mathrm{O}_{3}$ matrix particles, are found outside the wear scar (Figs. 11 and 12). Near the scar, long whiskers and matrix particles are present. The long whiskers indicate whisker pullout. Since the whiskers are largely unbroken it is plausible that they are somehow debonding from the matrix.

TEM analysis of pin wear scars from $1200^{\circ} \mathrm{C}$ tests also yielded features markedly different from room temperature specimens. Very few cracks were found, no wear particles were discovered and a few dislocation regions were detected (Fig. 13). Clearly the wear behavior at $1200{ }^{\circ} \mathrm{C}$ differs from that at $25^{\circ} \mathrm{C}$. TEM analysis of the virgin material indicates that it is free from voids, cracks and dislocations. Therefore, changes in the material after testing can be attributed to effects from the sliding. Figure 14 shows a TEM micrograph of a whisker which has reacted with impurities in the matrix, possibly iron, when slid at $1200{ }^{\circ} \mathrm{C}$. The reaction product, identified by the TEM diffraction pattern is iron silicide. Since iron silicide is liquid at $120{ }^{\circ} \mathrm{C}$ (Ref. 15) the remaining unreacted part of whisker may be debonding and, hence, easier to pull-out. Thus, at 
elevated temperatures the wear mode seems to be whisker loosening, pullout and breakup of matrix with possible whisker/matrix reactions.

$$
\text { C. Discussion of Experimental Results }
$$

The pin wear data indicate an increase of wear with test temperature. The reasons for this behavior are not clear but may be due to a variety of factors including the development of glassy surface layers and wear debris. To better understand the wear process, pin wear surfaces from room temperature and $120{ }^{\circ} \mathrm{C}$ tests were examined using scanning and transmission electron microscopy

The analyses indicate that at room temperature, the predominant failure mode is crack initiation and growth and subsequent delamination and removal of fractured particles. The analyses of high temperature specimens indicates that the predominant wear mode is by whisker pull out followed by increased matrix wear.

Although TEM analyses of the pin surface from the $1200{ }^{\circ} \mathrm{C}$ tests indicated that dislocations in both SiC whiskers and the alumina matrix were present (Fig. 13), supporting the theory that plastic behavior may be playing an important role in high temperature wear. However, few dislocations were found. Thus, the theory that plastic deformation and subsequent particle removal is dominating the high temperature wear behavior may not be likely under these test conditions.

One strong argument for a whisker pull-out wear mode is that the whiskers may be loosening at elevated temperatures due to differences in the thermal expansion coefficient between the $\mathrm{Al}_{2} \mathrm{O}_{3}$ matrix and the $\mathrm{SiC}$ 
whiskers. The thermal expansion coefficient for the alumina matrix is twice that of the Sic fibers (Table 1). Hence, as the material is heated, the whiskers loosen.

During hot consolidation or rather the initial production of the composite, at about $1600{ }^{\circ} \mathrm{C}$, there is no thermal stress between the whiskers and the matrix. Upon cooling, however, the matrix contracts more than the whiskers thus "clamping" the whiskers in compression. At temperatures lower than the consolidation temperature, the whiskers are in compression and the alumina matrix is in tension.

When sliding occurs, the friction force is tangential to the surface creating the tendency to pull or tug at the whiskers in the matrix. At low temperatures the whiskers are mechanically held in the matrix by the thermal compression. However, during elevated temperature testing or during high speed and load tests, which exhibit high frictional heating, the difference in thermal expansion lowers the "clamping" force on the whiskers. This allows them to more easily be pulled out of the matrix. Then the matrix, which is riddled with empty whisker pockets, cracks up and wears easily.

Evidence for this wear mode is found by examining the large numbers of unbroken, long whiskers outside the wear scar after testing at $1200{ }^{\circ} \mathrm{C}$. Wear debris from $25^{\circ} \mathrm{C}$ tests show only short whisker pieces and matrix presumably due to the fact that at lower temperatures the whiskers are strongly held by the matrix and are being broken by the wear process rather than being pulled out. 
TEM diffraction analyses indicate that at $1200^{\circ} \mathrm{C}$ some reaction between whisker and matrix may be occurring. The reaction products may have an effect on the friction and wear especially since there appears to be a glassy layer forming at the sliding surface as evidenced by the roll debris observed. Also, perhaps a low shear strength reaction product such as mullite or iron silicide, due to iron impurities in the whiskers or $\mathrm{Al}_{2} \mathrm{O}_{3}$, is forming at the matrix/whisker interface. If the reaction products are liquid at the sliding temperatures they may be allowing easier whisker pullout. SEM/Energy Dispersive analyses (EDS) were inconclusive for this material because the analysis area was larger than with the whisker diameter and spacing between whiskers.

Because the $\mathrm{SiCw}-\mathrm{Al}_{2} \mathrm{O}_{3}$ composite exhibits a dual wear mode tribobehavior any modelling of wear mechanisms must contain and explain the reason for the two wear modes. The following analysis attempts to do just that. By combining a thermal stress analysis with a tribothermal analysis, a model can be developed to describe the dual wear mode nature observed experimentally. In addition to determining why this dual wear mode behavior exists, the analysis can point out which material and test parameters have significant effects on tribological performance. With this information steps towards material improvements can be made.

\title{
V. THERMOMECHANICAL WEAR ANALYSIS
}

\author{
A. Nomenclature \\ $\mathrm{F}_{\mathrm{T}} \quad$ Total friction force in sliding contact, $\mathrm{N}$ \\ $F_{\text {BREAK }}$ Calculated fracture force for SiC whisker, $\mathrm{mN}$
}




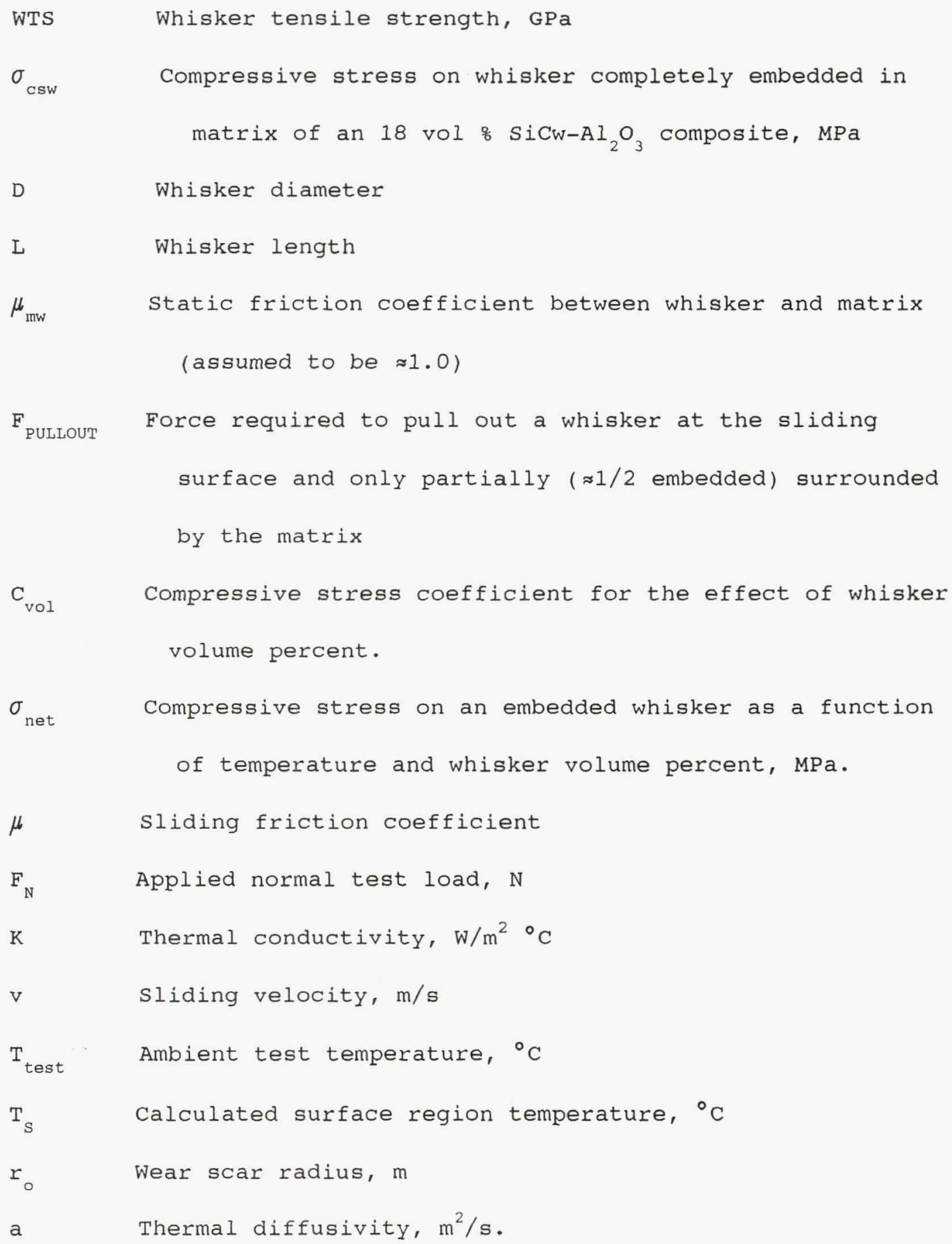




\section{B. Mode1}

The following analysis models the wear behavior of the $\mathrm{SiCw}-\mathrm{Al}_{2} \mathrm{O}_{3}$ composite through a force balance on the whiskers coupled with the effects of bulk and frictional heating due to sliding. In the model, the sliding friction force $\left(F_{T}\right)$ will be compared to the force required to fracture a whisker $\left(F_{\text {BREAK }}\right.$ ) and to the force required to pull out a whisker $\left(\mathrm{F}_{\text {PULLOUT }}\right)$ as a function of temperature in order to explain the dual wear mode. The model will include the effect of material parameters (such as thermal expansion coefficients, thermal conductivity, whisker strength, etc.) as well as the effect of tribological and test parameters (such as friction coefficient, sliding speed, load and temperature) on the wear behavior and may aid in taking steps in improving the composite.

Because the experimental program used a pin-on-disk configuration to generate wear conditions, the pin-on-disk configuration will be modelled here. Figure 15 shows, schematically, the wear specimens. It is assumed that the whiskers are pulled or pushed out of the matrix by the high frictional shear stresses present at the sliding interface or by a large counterface asperity as shown in an exaggerated fashion in Fig. 15 .

The tangential forces present in the sliding contact which can act to fracture or pull out whiskers are appreciable and are approximated by the experimentally measured friction force (i.e. $F_{N} * \mu$ ). For our tests, the available friction force $\left(F_{T}\right)$ is $26.5 \mathrm{~N} * \approx 0.7$ or about 
$18.6 \mathrm{~N}$. This force $\left(F_{T}\right)$ is much greater than the force required to break a whisker $\left(F_{\text {BREAK }}\right)$, which can be estimated as the whisker tensile strength multiplied by the whisker cross sectional area.

No data exists for the exact strength of the SiC whiskers used in this composite, however, Becker and Wei esitmate the whisker tensile strength, WTS, to be about $7 \mathrm{GPa}$ (Ref. 16). Their estimate is based upon tensile tests of like diameter, longer SiC fibers and larger diameter $(4 \mu \mathrm{m})$ but comparable length whiskers. Using this strength estimate (WTS $=7 \mathrm{GPa}$ ) and assuming that the average whisker is $0.75 \mu \mathrm{m}$ in diameter, the force required to break a whisker $\left(F_{\text {BREAK }}\right)$ is about $3.1 \mathrm{mN}$. Although this type of calculation is approximate, it can be readily seen that the forces present in the sliding contact are appreciable compared to the strength of the whiskers and, hence, generate wear debris.

When an asperity or simply the counterface contacts a whisker (as in Fig. 15), either the whisker can fracture as is seen experimentally in low temperature sliding tests, or the whisker can be pulled out of the matrix as is experimentally observed during sliding at higher temperatures. To summarize:

$$
F_{T}>>F_{\text {BREAK }}
$$

where $F_{T}$ is the force available at the surface by the counterface to pull (or push) a whisker out of the matrix and $F_{\text {BREAK }}$ is the calculated force necessary to break a SiC whisker. 
The force required to pull out a whisker, $F_{\text {PULLOUT' }}$ is equal to the compressive stresses acting on the whisker due to the matrix, $\left(\sigma_{\mathrm{CSW}}\right)$ multiplied by both the whisker surface area ( $\pi \mathrm{DL}$ ) and the friction coefficient between the matrix and the whisker, $\mu_{\mathrm{mw}}$. By comparing the forces required to pull out a whisker, $F_{\text {pullout' }}$ to the force required to fracture a whisker, $F_{\text {BREAK' }}$ a prediction of the outcome of a whiskercounterface interaction can be made (i.e., the whisker is pulled out or broken).

For this analysis, it is assumed that the bond between the whiskers and the matrix is purely mechanical, arising from friction forces. Chemical bonding is neglected for this material system and it if exists, it is probably small. This assumption is based upon the widely held viewpoint that for a ceramic matrix composite to show improved toughness, as this composite does, the chemical bonding between the whiskers and the matrix is small. Therefore, cracks are branched and deflected by the whiskers rather than propagating through them. Thus, the force required to remove a whisker from the surrounding matrix, $F_{\text {PULLOUT' }}$ is equal to the frictional forces on the whiskers. For simplicity, $\mu_{m w}$ is considered to be about 1.0 which is typical for unlubricated ceramics and hence will be dropped in the following equations.

Whiskers that are pulled from the matrix either by a counterface asperity or merely by the tangential friction stresses are necessarily exposed to the sliding surface. As such, they cannot be completely embedded in or surrounded by the matrix. Therefore, the actual surface area upon which the compressive matrix stresses act on the whiskers is 
only a fraction of the total area, $\pi D L$. If a whisker were completely exposed to the sliding surface, the surface area acted upon would be zero and if completely surrounded, the surface area would be equal to $\pi \mathrm{DL}$. For the following analysis, it will be assumed that the whiskers are only partially exposed and that the compressive matrix stresses act upon about one-half of the total whisker area or $\pi \mathrm{DL} / 2$.

At lower temperatures the compressive stresses on the whiskers due to the matrix are very high (on the order of $750 \mathrm{MPa}$ ) and thus the force required to pull out a whisker $\left(F_{\text {PULLOUT }}\right)$ is greater than the whisker fracture force $\left(F_{\text {BREAK }}\right)$ :

$$
\begin{aligned}
\mathrm{F}_{\text {PULLOUT }} & >\mathrm{F}_{\text {BREAK }} \\
\left(\sigma_{\mathrm{CSW}}\right) *(\pi \mathrm{DL} / 2) & >\operatorname{WTS} *\left(\pi \mathrm{D}^{2} / 4\right)
\end{aligned}
$$

where WTS is the whisker tensile strength, $D$ is the diameter and L is the average whisker length.

Under this condition, characteristic of low temperatures, the whiskers are fractured rather than being pulled out during sliding and wear follows brittle behavior.

At higher temperatures, thermal expansion of the matrix reduces the compressive stress on the whiskers and the inequality reverses so that:

$$
\begin{aligned}
\mathrm{F}_{\text {PULLOUT }} & <\mathrm{F}_{\text {BREAK }} \\
& \text { or } \\
\left(\sigma_{\mathrm{CSW}}\right) *(\pi \mathrm{DL} / 2) & <(\text { WTS }) *\left(\pi \mathrm{D}^{2} / 4\right)
\end{aligned}
$$

Under this condition, the whiskers are pulled out of the matrix during sliding. The second wear process, namely whisker pullout, which occurs 
at higher temperatures, leaves the matrix riddled with holes, or empty whisker pockets, which act as flaws or fracture initiation sites and lead to higher wear.

The main parameters affecting both the whisker strength and the compressive stresses on the whiskers is the near surface temperature of the specimens (i.e., within a few whisker diameters from the surface). The temperature is, in turn, affected by the tribological and test parameters such as friction coefficient, load, and velocity as well as material parameters such as thermal conductivity and diffusivity.

\section{Thermoelastic Stress Analysis}

Since brittle materials, such as this composite, behave elastically up to the fracture point, we can determine the stresses in the material using elasticity theory. The magnitude of the compressive stresses on the whiskers and on the matrix have been experimentally measured and analytically modelled (Refs. 17 to 19). The models are based upon the application of Hooke's Law in three dimensions where the residual thermal strains are calculated by elasticity theory.

In general, the whiskers are modelled as being completely embedded in an infinite isotropic ceramic matrix. Although in reality the elastic constants for the whiskers are not isotropic, when isotropic values are used reasonable results are obtained (i.e., they agree with other more rigorous tests such as experimental stress analysis). The analytical method and results presented here are loosely based upon just such an analysis by Eshelby (Ref. 20). To compensate for whisker interactions and non-isotropic elastic constants, a self-consistent 
approach was used, i.e., the model is of a single whisker completely embedded in an infinite matrix which has the elastic properties of the $\mathrm{SiCW}-\mathrm{Al}_{2} \mathrm{O}_{3}$ composite.

The analysis method, first outlined by Mori and Tanaka (Ref. 21), was applied to this $\mathrm{Al}_{2} \mathrm{O}_{3}$-SiC material by Majumdar and Kupperman (Ref. 18). The analysis consists of setting up a three-dimensional matrix of Hooke's Law and following the stress and strain fields in a SiC whisker as temperature is changed.

Majumdarand Kupperman (Ref. 18) applied this approach to the $\mathrm{SiCW}-\mathrm{Al}_{2} \mathrm{O}_{3}$ material system and their results are shown in $\mathrm{Fig}$. 16. As can be clearly seen from the figure, the compressive stresses on the whisker are highest at room temperature and decrease linearly with temperature. Their analytical results were also in excellent agreement with experimental stress analysis results obtained by neutron diffraction techniques. This helps increase confidence in their stress analysis method.

The results of the analytical stress analysis from Ref. 18 can be summarized as follows. During cooling from the initial consolidation temperatures $\left(\approx 1650^{\circ} \mathrm{C}\right)$ differences in the coefficient of thermal expansion (CTE) between the $\mathrm{SiC}$ whiskers and the $\mathrm{Al}_{2} \mathrm{O}_{3}$ matrix cause thermal stresses to form which are relieved by matrix creep. At temperatures below about $1350{ }^{\circ} \mathrm{C}$, however, the matrix is stiffened and creep is no longer a dominant factor in stress relief thus thermal stresses develop. Because the CTE for the whiskers is about one-half 
that of the matrix the whiskers are placed in compression. As the temperature further decreases, the residual stresses at the whisker/ matrix interface continue to rise in a more or less linear fashion. It is this compressive stress on the whiskers which helps to hold them in the matrix during sliding.

The following curve-fit equation describes the variation of whisker compressive stresses with temperature:

$$
\sigma_{\mathrm{csw}}=1000 \mathrm{MPa}-0.741 \mathrm{MPa} /{ }^{\circ} \mathrm{C} \times \mathrm{T}
$$

for a composite containing $18 \%$ by volume SiC whiskers.

Majumdar et al. (Ref. 19) extended their analyses to include the effect of whisker volume percent. The average strains (and hence stresses) were found to decrease with SiC content in a more or less linear fashion as shown in Fig. 17. The decrease in stress was attributed to a dilution effect of the matrix stress effect by the SiC whiskers.

A curve fit for this effect, taken from Fig. 17 is given by the dimensionless coefficient as follows:

$$
\mathrm{C}_{\mathrm{vOl}}=[1-0.01449(\% \text { SiC whiskers }-18 \%)]
$$

Equation (5) can be considered accurate for compositions ranging from about 15 to 40 vol o SiC whiskers.

By combining Eqs. (4) and (5) with the effect of bulk temperature, we get an equation which relates the compressive stresses on a fully embedded whisker with temperature and composition. 


$$
\begin{gathered}
\sigma_{\text {net }}(\mathrm{T}, \% \mathrm{SiCW})=\sigma_{\mathrm{csw}} * \mathrm{C}_{\mathrm{vol}} \\
\text { or } \\
\sigma_{\text {net }}(\mathrm{T}, \& \mathrm{SiC} \text { Whiskers })=\left\{1000 \mathrm{MPa}-0.741 \mathrm{MPa} /{ }^{\circ} \mathrm{C} \times \mathrm{T}\right\} \\
*\{1-801449(\% \mathrm{SiC}-18 \%)\}
\end{gathered}
$$

where $\sigma_{\text {net }}$ represents the stress on a whisker due to the matrix as a function of temperature and composite whisker content. To use Eq. (6) to calculate $\mathrm{F}_{\text {pullout }}$ Eq. (2) can be employed, substituting $\sigma_{\text {net }}$ for $\sigma_{\mathrm{csw}}$.

From a tribological point of view, the key aspects of Eq. (6) are that the compressive stresses on the whiskers decrease linearly with temperature and with volume percent SiC whiskers.

\section{Tribothermal Analysis}

If the composite were applied in a static situation, i.e., without sliding, the above analysis would be sufficient to describe the stress state of the whiskers, assuming that the sample is in thermal equilibrium with the ambient temperature. However, during sliding, frictional heating can greatly increase the near surface temperatures, significantly altering the whisker stresses and, hence, potentially the triboproperties of the material.

Many researchers have studied the problem of determining surface temperatures and near surface region temperature rise which occur as a consequence of frictional heating (Refs. 13 and 22). Although specific details do vary, it is generally accepted that the temperature rise is a function of such variables as load, speed, friction coefficient, thermal conductivity and diffusivity as well as the type of environment present. 
To describe the temperature rise occurring for pin specimens studied here, an analysis by Ashby (Ref. 22) has been found to be useful.

Figure 18 shows the physical situation described by Ashby's model which is based upon the assumption that the frictional heating is conducted away from the sliding contact into the pin and its holder and also into the disk. Convection is neglected and the mean heat diffusion distance (the near surface region of the sliding contact) has been approximated by 1.6 times the contact radius, $r_{o^{\prime}}$ as suggested by Ashby (Ref. 22). The following equation mathematically describes the "bulk" heating of the specimens, i.e., the surface temperature of the pin in the region near the sliding interface, $\mathrm{T}_{\mathrm{S}}$.

$$
\mathrm{T}_{\mathrm{S}}=\mathrm{T}_{\mathrm{TEST}}+\left\{\mu \mathrm{F}_{\mathrm{N}} \mathrm{V} /\left(2 \pi^{1 / 1} \mathrm{Kr}_{0}\right)\right\} *\left[1+\pi /\left(2 \tan ^{-1}\left(2 \pi \mathrm{a} / \mathrm{Vr}_{0}^{1 / 2}\right]^{-1}\right.\right.
$$

where:

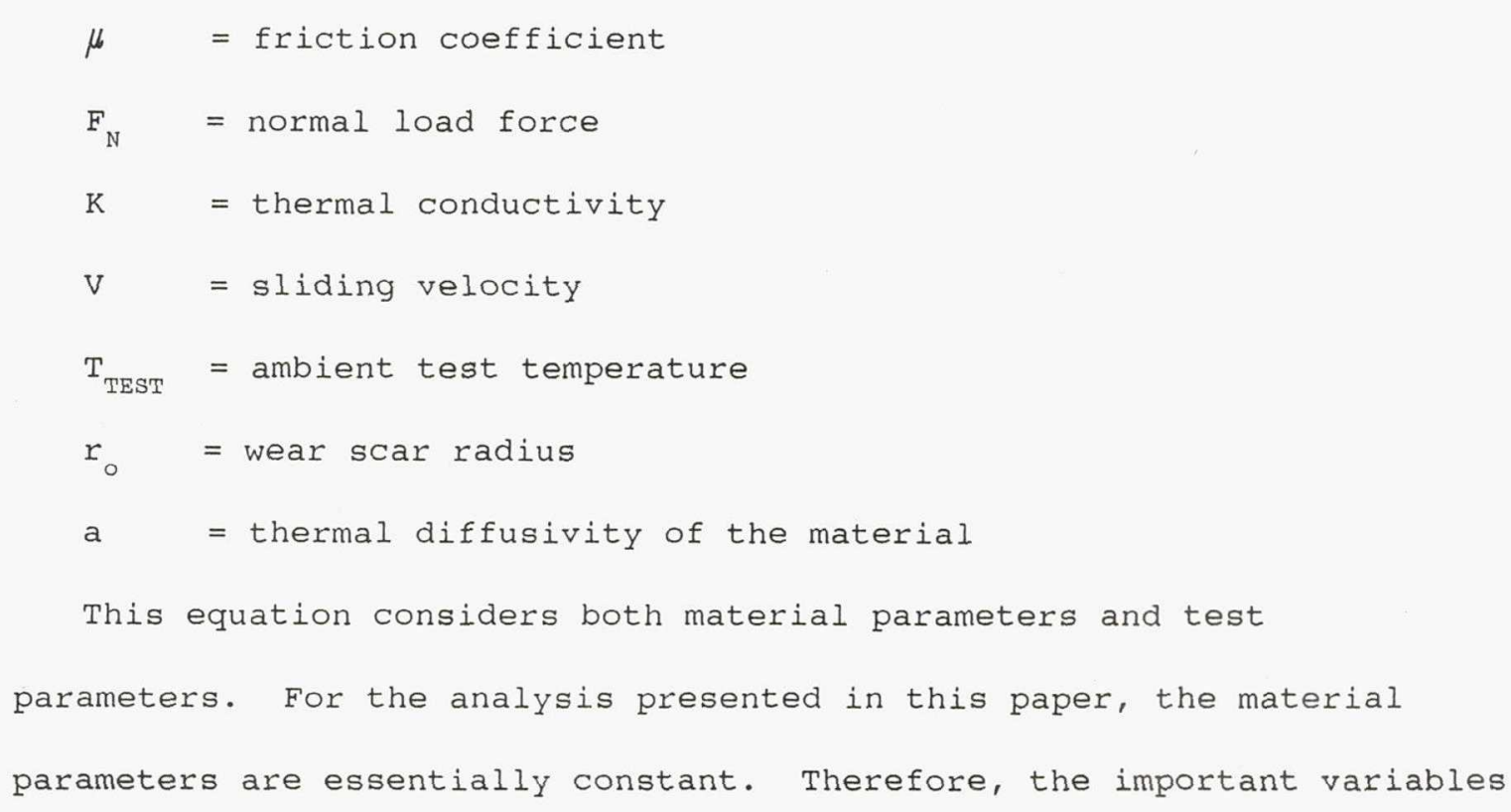


are load, speed, friction coefficient and $\mathrm{T}_{\mathrm{TEST}}$. As these are increased, the near surface region temperature increases and thus the compressive stresses on the whiskers decrease. From these considerations, it is possible to have a room temperature test which, because of high loads and/or sliding speeds, leading to high near surface temperatures, exhibits of whisker pullout.

The magnitude of the frictional heating effects can be seen by examining Table 3. This table shows the test conditions and calculated surface temperatures for the tests conducted in the experimental work (Ref. 9). It can be seen that even at moderate load and sliding velocity, the frictional temperatures rise above the ambient by about 400 to $500{ }^{\circ} \mathrm{C}$. This heating can greatly influence the wear mode of the materials by changing the stresses on the whiskers in the region of sliding.

E. Discussion of Analytical Results

The results of the preceding analyses and the implications on the wear behavior are illustrated graphically in Fig. 19 which are plots for both the pullout force $\left(F_{\text {PULLOUT }}\right)$ on the whiskers and the whisker fracture force $\left(\mathrm{F}_{\text {BREAK }}\right)$ versus the near surface temperatures for a 25 vol $\%$ $\mathrm{SiCW}-\mathrm{Al}_{2} \mathrm{O}_{3}$. The inequality reversal or crossover point between the whisker fracture force $\left(F_{\text {BREAK }}\right.$ ) and the compressive forces on the whiskers ( $F_{\text {pULLOUT }}$ ), shown graphically in Fig. 19 as the "transition region" and described by Eqs. (2) and (3), gives a plausible reason why dual wear mechanisms (namely whisker pull-out or generalized fracture) 
exist for the composite material. As described previously, when the whisker fracture force is less than the compressive forces holding the whiskers in the matrix, interactions with the sliding counterface will fracture the whiskers. This behavior occurs at temperatures below $1200{ }^{\circ} \mathrm{C}$. At temperatures above about $1200{ }^{\circ} \mathrm{C}$, the compressive forces holding the whiskers in the matrix drop below the whisker fracture force and interactions with the counterface will result in whisker pull-out rather than fractures.

The width of the transition region is based upon tribodata scatter (namely friction variation) and uncertainties in the analysis and is typically $\approx \pm 100{ }^{\circ} \mathrm{C}$. One of the major contributors to a large transition region is the effect of whisker length. Its effect can be seen in Eqs. (2) and (3). Since the whiskers range in length from about 10 to $60 \mu \mathrm{m}$, the pull out force and hence the transition point can vary significantly (Fig. 20). From this figure it can be seen that the transition point changes from about $1000{ }^{\circ} \mathrm{C}$ for short $(10 \mu \mathrm{m})$ whiskers to about $1300{ }^{\circ} \mathrm{C}$ for long $(60 \mu \mathrm{m})$ whiskers. Thus one would expect composites made with predominantly shorter whiskers to suffer from whisker pull out at lower temperatures than composites made with longer whiskers. Composites made with longer whiskers, however, would not necessarily be best since other mechanical properties such as toughness and processing ease can be degraded with unduly long whiskers.

By examining the equations describing the stress conditions on the whiskers, some insight into the effects of variables on the potential 
wear behavior can be determined. For example, Eq. (6) relates the stresses on the whiskers as a function of bulk temperature and composite whisker content. By varying the whisker content from $18 \%$ to $40 \%$ the transition temperature decreases by approximately $350{ }^{\circ} \mathrm{C}$ (Fig. 21). Therefore, the whisker content of the composite may have a significant effect in determining the wear mode. This effect needs to be verified experimentally, however, as changes in whisker content can also affect the toughness in an inconsistent manner thereby having an unknown effect on triboperformance.

Changes in test conditions, such as load, velocity and ambient test temperature directly affect the calculated sliding temperature as in Eq. (7). As these variables increase, the sliding temperatures increase also. Of course, increases in friction also increase the temperature indicating that lubricating the sliding contact will reduce the temperature and may have a significant effect on the wear behavior. F. Comparison to Experimental Data Comparing the analytical results to experimental results is simply a matter of calculating the near surface region temperatures for tribo tests conducted with this material and seeing whether the model predicts the experimentally determined wear mode.

Table 4 shows the calculated temperatures and experimentally observed wear modes for tests conducted at ambient temperatures of 25, 600 and $1200^{\circ} \mathrm{C}$. Figure 19 also shows the experimental data points (using the calculated temperatures) plotted with the predicted curves. 
The model correlates the wear behavior of these tests very well. Therefore, it may be useful in predicting the wear behavior of other similar materials under a wide variety of test conditions.

One interesting point is that the wear factors experimentally determined in previous work indicate a maximum at a calculated sliding temperature of $1071^{\circ} \mathrm{C}$. This temperature is near the transition point of $\approx 1200{ }^{\circ} \mathrm{C}$. There may be a relationship between maximum wear and the transition in wear behavior. Other authors have also measured wear maximums with the alumina-silicon carbide composite (Ref. 8).

\section{CONCLUDING REMARKS}

The tribological behavior of whisker reinforced ceramics is complex. The wear mechanisms can be affected by the environment, sliding conditions, counterface material and composition of the composite. Based upon the experimental results and the model, an exhaustive series of experiments could be envisioned to further test and refine the analyses. These experiments might include tests in inert atmospheres at a wide range of loads, sliding speeds, temperatures and whisker volume content.

In addition, other ceramic composite material systems could be tested. For example, testing of a zirconia reinforced alumina $\mathrm{ZrO}_{2}-$ $\mathrm{Al}_{2} \mathrm{O}_{3}$ could help to verify the effect of the coefficient of thermal expansion (CTE) of the reinforcement phase on pin wear. With $\mathrm{SiCW}-\mathrm{Al}_{2} \mathrm{O}_{3}$ the pin wear increased with temperature because the differences in the CTE between SiC and $\mathrm{Al}_{2} \mathrm{O}_{3}$ lead to a reduction in the compressive whisker stresses. However, with $\mathrm{ZrO}_{2}-\mathrm{Al}_{2} \mathrm{O}_{3}$ the reverse would probably occur 
because the CTE of $\mathrm{ZrO}_{2}$ is larger than the CTE of $\mathrm{Al}_{2} \mathrm{O}_{3}$. In fact, research by Yust and Devore on $\mathrm{ZrO}_{2}-\mathrm{Al}_{2} \mathrm{O}_{3}$ did display a reduction in pin wear with temperature (Ref. 23). Although their tests were not for a whisker reinforced composite, the change in the $\mathrm{ZrO}_{2}-\mathrm{Al}_{2} \mathrm{O}_{3}$ stress state with temperature may have played a role similar to that of $\mathrm{SiCW}-\mathrm{Al}_{2} \mathrm{O}_{3}$. The results also indicate that the $\mathrm{SiCW}-\mathrm{Al}_{2} \mathrm{O}_{3}$ wear properties might be improved by inhibiting whisker pull-out. This could be accomplished through the use of a high friction whisker coating or by using variable diameter whiskers which may promote whisker/matrix interlocking. These techniques, however, may reduce toughness.

Furthermore, the model defines the limits or envelope of useable test conditions, beyond which the materials wear properties degrade. By using the analysis presented, the effects of a wide variety of variables can be more or less predicted.

It is clear that the wear behavior of whisker reinforced ceramics is complex. The addition of the second phase (SiCw) radically alters the materials properties. Although the composite system may be more difficult to study, its superior properties (toughness and wear resistance) make it an ideal candidate for demanding applications. Therefore it is worthwhile to conduct research in this area.

Finally, much of what is learned by experimental testing could probably never be deduced. By doing careful experimental research and explaining the results with the help of a useful model, methods to improve a materials properties can be determined. 


\section{REFERENCES}

1. P.F. Becher and T.N. Tiegs, Adv. Ceram. Mater., 3: 148 (1988).

2. H.E. Helms and S.R. Thrasher, Engineering Applications of Ceramics Materials, American Society for Metals, Metals Park, OH. (1985).

3. K.C. Ludema and O.O. Ajayi, "Wear Mechanisms in Ceramic Materials Engine Applications," Proceedings of the 22n Automtive Technology Development Contracts' Coordination Meeting, Dearborn, MI, SAE Publication P-155, pp. 337-341 (1985).

4. H.E. Sliney and D.L. Deadmore, "Friction and Wear of Oxide-Ceramic Sliding Against IN-718 Nickel Base Alloy at 25 to $800{ }^{\circ} \mathrm{C}$ in Atmospheric Air," NASA TM-102291, August 1989.

5. K. Fukuda, Y. Sato, T. Sato, and M. Veki, "Wear Properties of SiC Whisker Reinforced Ceramics Against Bearing Steel," Presented at the Tribology of Composite Materials, 1-3 May, 1990, Oak Ridge, TN.

6. M. Bohmer and E.A. Almond, Mater. Sci., A 105/106: 105 (1988).

7. C.S. Yust, J.M. Leitmaker, and C.E. DeVore, Wear, 122: 151 (1988).

8. C.S. Yust and L.F. Allard, STLE Trans., 32: 331 (1989).

9. C.S. Yust and L.F. Allard, Ceramic Materials and Components for Engines, (V.J. Tennery ed.), American Ceramic Society, p. 1212 (1989) .

10. C. Dellacorte, S.C. Farmer, and P.O. Book, "Experimentally Determined Wear Behavior of an $\mathrm{Al}_{2} \mathrm{O}_{3}-\mathrm{SiC}$ Composite from 25 to $1200{ }^{\circ} \mathrm{C}$, NASA TM-102549, 1990. 
11. J. Homeny, and W.L. Vaughn, Mater. Res. Soc. Bull., 1266 (1987).

12. H.E. Sliney and C. DellaCorte, "A New Test Machine for Measuring Friction and wear in Controlled Atmospheres to $1200^{\circ} \mathrm{C}, "$ NASA TM-102405, 1989.

13. M.B. Peterson and W.O. Winer, Wear Control Handbook, ASME, 475 $(1980)$

14. P. Boch, F. Platon and G. Kapelski, "Effect of Temperature and Environment on Wear and Friction of $\mathrm{Al}_{2} \mathrm{O}_{3}$ and SiC Ceramics," Proceedings of the fifth International Congress on Tribology, Helsinki, Finland, (K. Holmberg and I. Nieminen, eds.) pp. 114-119 (1989).

15. E.M. Levin, C.R. Robbins, and K.F. McMurdie, Phase Diagrams for Ceramists, American Ceramic Society, p. 59, Figure 81 (1964).

16. P.F. Becher and G.C. Wei, Am. Ceram. Soc. Comm. 67: C-267 (1984).

17. Z. Li and R.C. Bradt, J. Am. Ceram. Soc., 72: 70 (1989).

18. S. Majumdar, D. Kupperman and J. Singh, J. Am. Ceram. Soc., 71: $858(1988)$.

19. S. Majumdar and D. Kupperman, J. Am. Ceram. SoC., 72: 312 (1989). 20. J.D. Eshelby, J.D, Proc. R. Soc. London, A, 241: 376 (1957).

21. T. Mori and K. Tanaka, Acta Metall., 21: 571 (1973).

22. M.F. Ashby, "The Development of Wear Mechanisms Maps," Proceedings of the International Workshop on Wear Modelling, Argonne National Laboratory, (F.A. Nichols, F.A., A.E. Michael, and L.A. Northcutt, eds.) pp. 25-59 (1988). 
23. C.S. Yust and C.E. DeVore, STLE Trans., 33: 573 (1990).

TABLE 1. - MANUFACTURER'S STRENGTH AND PROPERTY DATA*

\begin{tabular}{|c|c|c|c|c|}
\hline & \multicolumn{4}{|c|}{ Material } \\
\hline Property & $\mathrm{Al}_{2} \mathrm{O}_{3}$ & $\mathrm{SiC}$ & $\mathrm{Al}_{2} \mathrm{O}_{3}-\mathrm{SiC}$ & $\mathrm{ZrO}_{2}$ \\
\hline Denisty, g/cc & 3.9 & 3.1 & 3.74 & 5.7 \\
\hline Young's modulus, GPa & 386 & 406 & 393 & 200 \\
\hline $\begin{array}{l}\text { Vickers hardness, } \\
\mathrm{kg} / \mathrm{mm}^{2}\end{array}$ & 2000 & 2800 & 2125 & 1050 \\
\hline Toughness, $\mathrm{MPa} / \mathrm{m}$ & 4.2 & 3.8 & 8.8 & 8.2 \\
\hline $\begin{array}{l}\text { Thermal expansion } \\
\text { coefficient, } /{ }^{\circ} \mathrm{C}\end{array}$ & $8.0 \times 10^{-6}$ & $4.0 \times 10^{-6}$ & $6.0 \times 10^{-6}$ & $9.2 \times 10^{-6}$ \\
\hline $\begin{array}{l}4 \text { Point bend strength, } \\
\mathrm{MPa} \text { at R.T. }\end{array}$ & 344 & 448 & 641 & 630 \\
\hline Poisson's ratio & .23 & .12 & .23 & .23 \\
\hline $\begin{array}{l}\text { Thermal conductivity, } \\
\mathrm{W} / \mathrm{M}^{\circ} \mathrm{C}\end{array}$ & 22 & 12.5 & 22.3 & 2.0 \\
\hline $\begin{array}{l}\text { Thermal diffusivity, } \\
\mathrm{m}^{2} / \mathrm{s}\end{array}$ & $8.0 \times 10^{-6}$ & $6.0 \times 10^{-2}$ & $1.35 \times 10^{-5}$ & $7.0 \times 10^{-7}$ \\
\hline
\end{tabular}

"ARCO Chemical Co., Green, S.C. and Carborndum Co., Niagra Falls, NY

TABLE 2. - FRICTION AND WEAR DATA SUMMARY (From Ref. (9)

\begin{tabular}{|c|c|c|c|}
\hline $\begin{array}{c}\text { Test } \\
\text { temperature }\end{array}$ & $\begin{array}{c}\text { Coefficient } \\
\text { of friction, } \\
\mu\end{array}$ & $\begin{array}{c}\text { Wear factor, } \\
\text { Kpin } \mathrm{mm}^{3} / \mathrm{Nm}\end{array}$ & $\begin{array}{c}\text { Wear factor } \\
\text { Kdisk }\end{array}$ \\
\hline $1200{ }^{\circ} \mathrm{C}$ & $0.58 \pm .15$ & $(1.1 \pm .5) \times 10^{-6}$ & $(5.1 \pm 2.0) \times 10^{-7}$ \\
$800{ }^{\circ} \mathrm{C}$ & $.72 \pm .22$ & $(6.1 \pm 1.0) \times 10^{-7}$ & $(4.2 \pm 2.0) \times 10^{-7}$ \\
$600{ }^{\circ} \mathrm{C}$ & $.60 \pm .10$ & $(1.5 \pm .5) \times 10^{-6}$ & $(7.0 \pm 2.0) \times 10^{-7}$ \\
$25{ }^{\circ} \mathrm{C}$ & $.74 \pm .10$ & $(2.4 \pm .5) \times 10^{-7}$ & $(7.7 \pm 4.0) \times 10^{-7}$ \\
\hline
\end{tabular}

Uncertainties represent data scatter band. 


\section{TABLE 3. - TEST CONDITIONS AND CALCULATED}

PIN SURFACE TEMPERATURES FOR DATA

OBTAINED IN Ref. 9

\begin{tabular}{|c|c|c|c|c|}
\hline $\mathrm{T}_{\text {TEST }_{\mathrm{C}}}$ & $F_{N}$, & $\begin{array}{l}\mathrm{V}, \\
\mathrm{m} / \mathrm{s}\end{array}$ & $\mu$ & $\underset{{ }^{\circ} \mathrm{C}}{\mathrm{T}_{\mathrm{s}}}$ \\
\hline 25 & 26.5 & 2.7 & 0.74 & 605 \\
\hline 600 & 26.5 & 2.7 & .60 & 1071 \\
\hline 800 & 26.5 & 2.7 & .72 & 1361 \\
\hline 1200 & 26.5 & 2.7 & .58 & 1655 \\
\hline
\end{tabular}

*Calculations done for 25 vol \% SiC whisker reinforced $\mathrm{Al}_{2} \mathrm{O}_{3}$ composite. Wear scar radius $=1 \mathrm{~mm}$, thermal diffusivity

$\approx 1.35 \times 10^{-5} \mathrm{~m}^{2} / \mathrm{s}$, thermal conductivity

$\approx 22.3 \mathrm{w} / \mathrm{m}^{\circ} \mathrm{C}$. Calculated surface

temperature uncertainties are $\approx 100{ }^{\circ} \mathrm{C}$.

TABLE 4. - COMPARISON OF PREDICTED WEAR MODE AND EXPERIMENTALLY DETERMINED WEAR MODE

\begin{tabular}{|r|c|l|l|}
\hline $\begin{array}{r}T_{\text {TEST }} \\
{ }^{\circ} \mathrm{C}\end{array}$ & $\mathrm{T}_{\mathrm{s}}$ (Calculated), & Mode predicted & Mode observed \\
\hline 25 & ${ }^{\circ} \mathrm{C}$ & $\begin{array}{l}\text { Whisker fracture } \\
\text { Transition - Mixed } \\
\text { mode }\end{array}$ & $\begin{array}{l}\text { Whisker fracture } \\
\text { Mixed mode }\end{array}$ \\
800 & $\begin{array}{l}\text { Whisker pullout } \\
\text { Whisker pullout }\end{array}$ & $\begin{array}{l}\text { Whisker pullout } \\
\text { Whisker pullout }\end{array}$ \\
\hline
\end{tabular}

*Test load $26.5 \mathrm{~N}$, Test Velocity $\approx 2.7 \mathrm{~m} / \mathrm{s}$. Calculated surface temperature uncertainties are $\approx 100{ }^{\circ} \mathrm{C}$. 


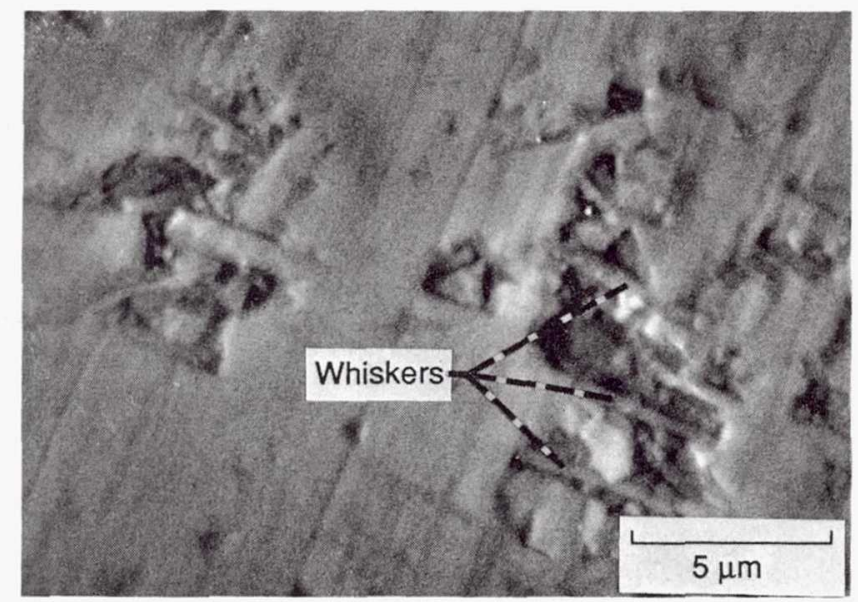

Figure 1.-SEM micrograph of ceramic surface showing orientation of whiskers in planes parallel to surface and sliding plane.

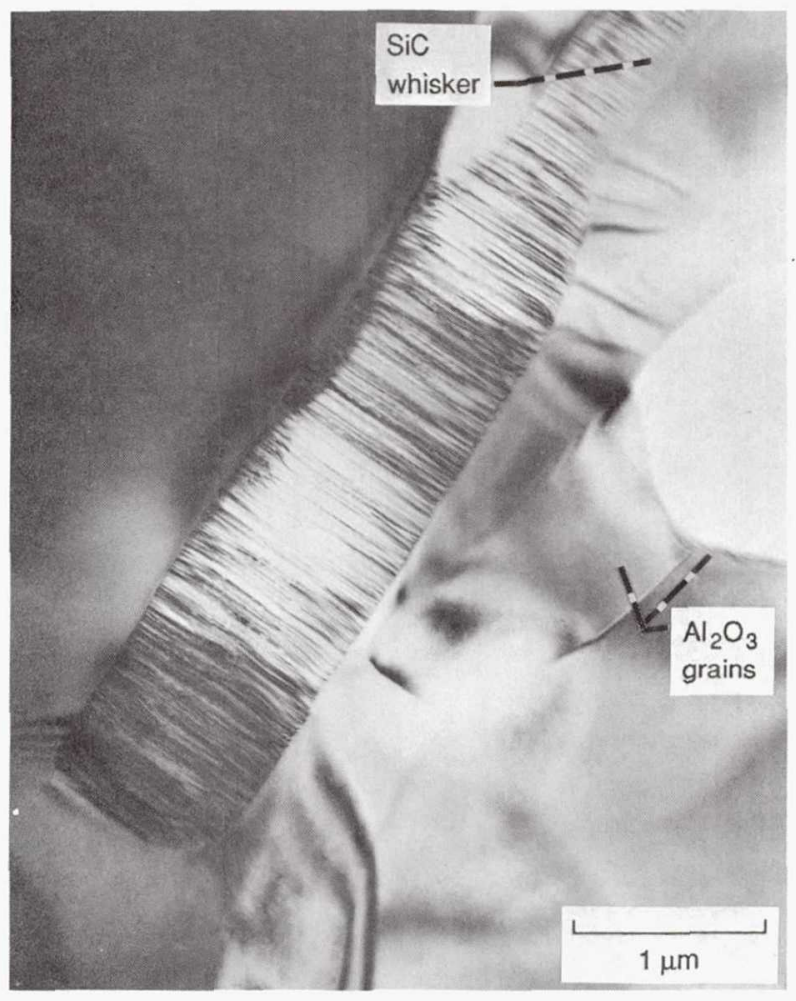

(a) Interface between whiskers and matrix is free from inclusions, large scale asperities, voids, etc. Alumina matrix grains visible.

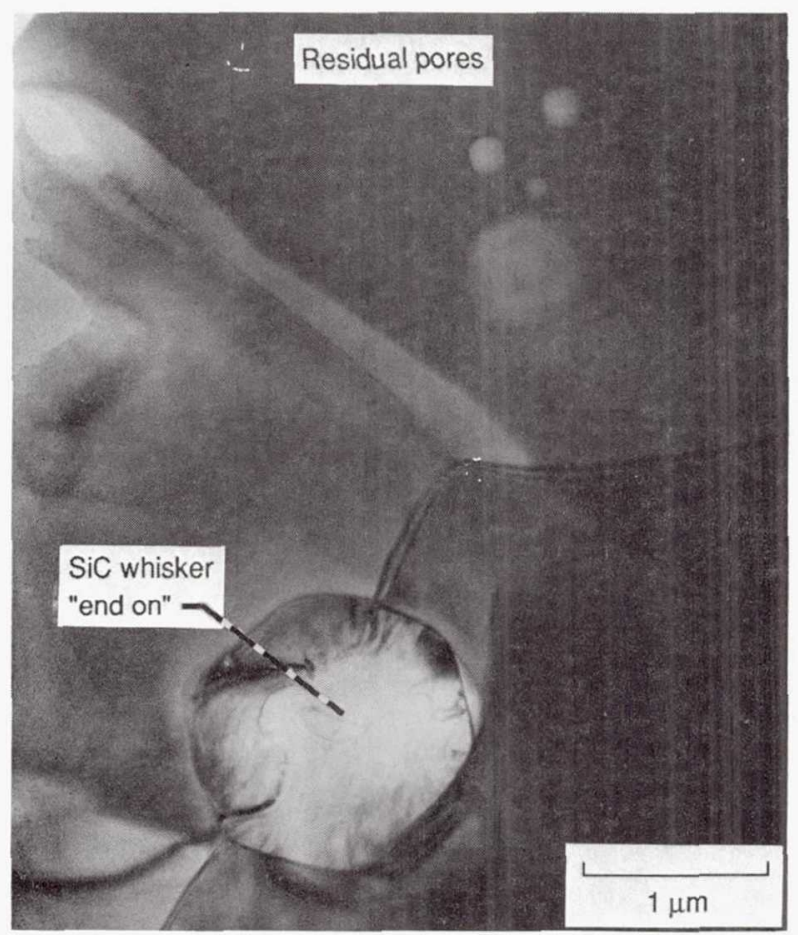

(b) Whiskers cross-section, some small enclosed pores, matrix grain structure.

Figure 2.-TEM micrograph of virgin (unslid) material. 


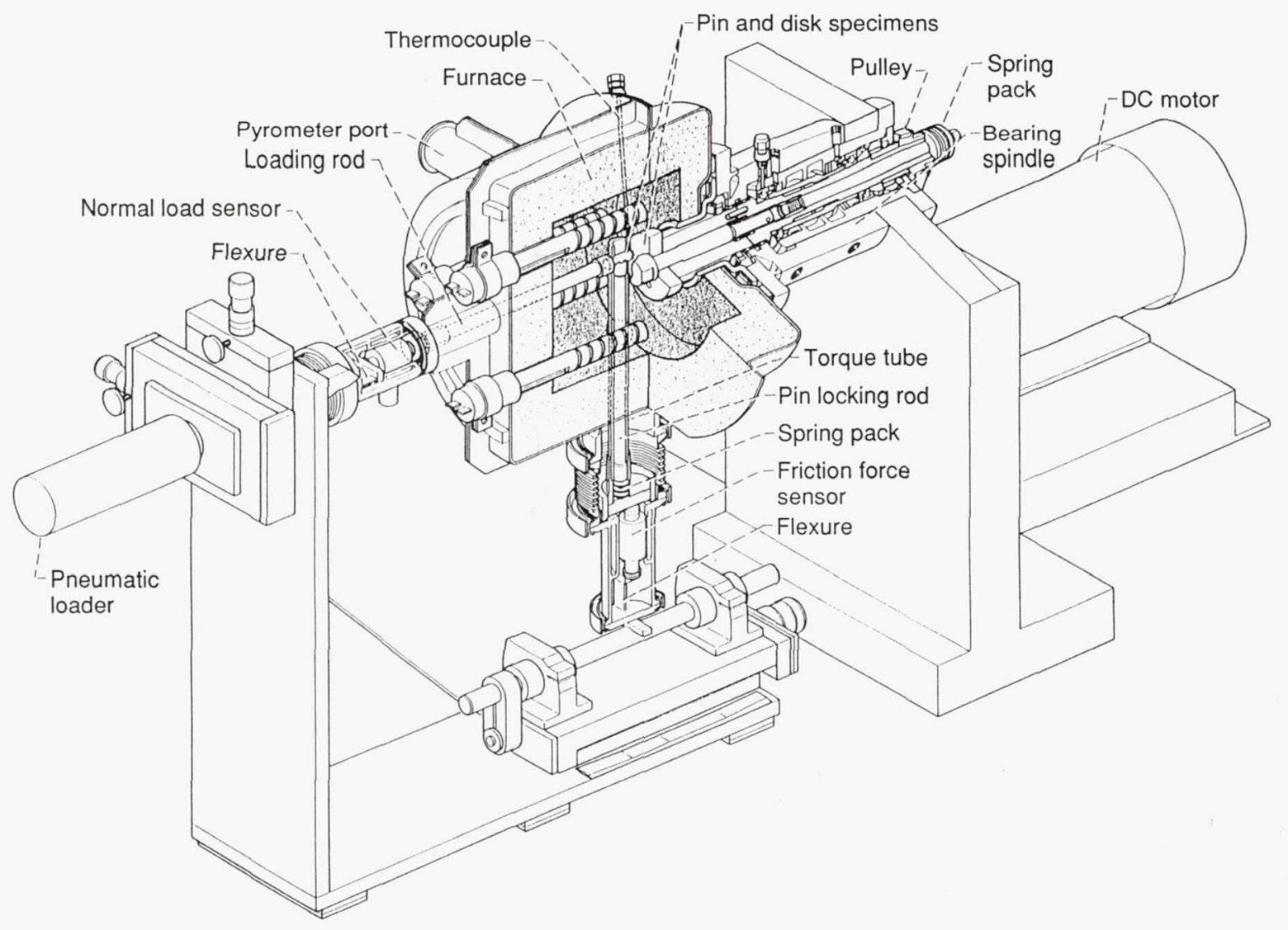

Figure 3.- High temperature friction and wear apparatus.

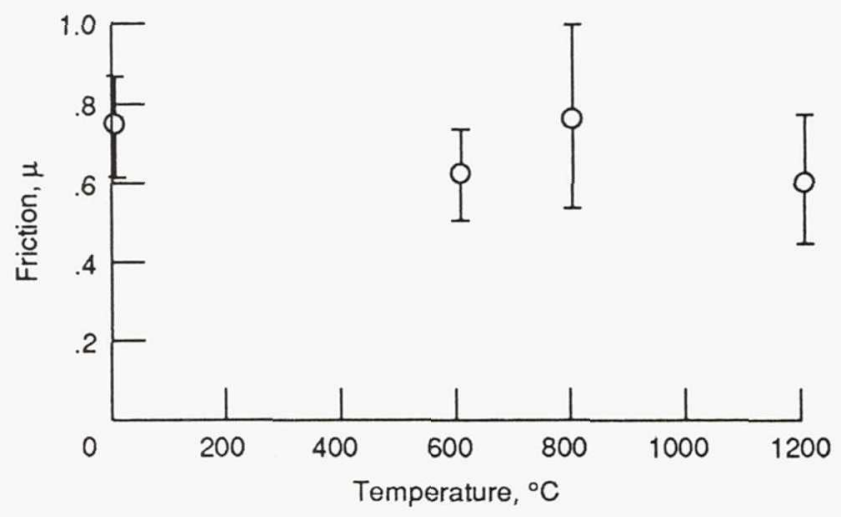

Figure 4.-Friction coefficient versus test temperature for the $\mathrm{Al}_{2} \mathrm{O}_{3}-\mathrm{SiC}$ composite sliding against itself in air at $2.7 \mathrm{M} / \mathrm{s}, 26 \mathrm{~N}$ load. Error bars represent data scatter band. 


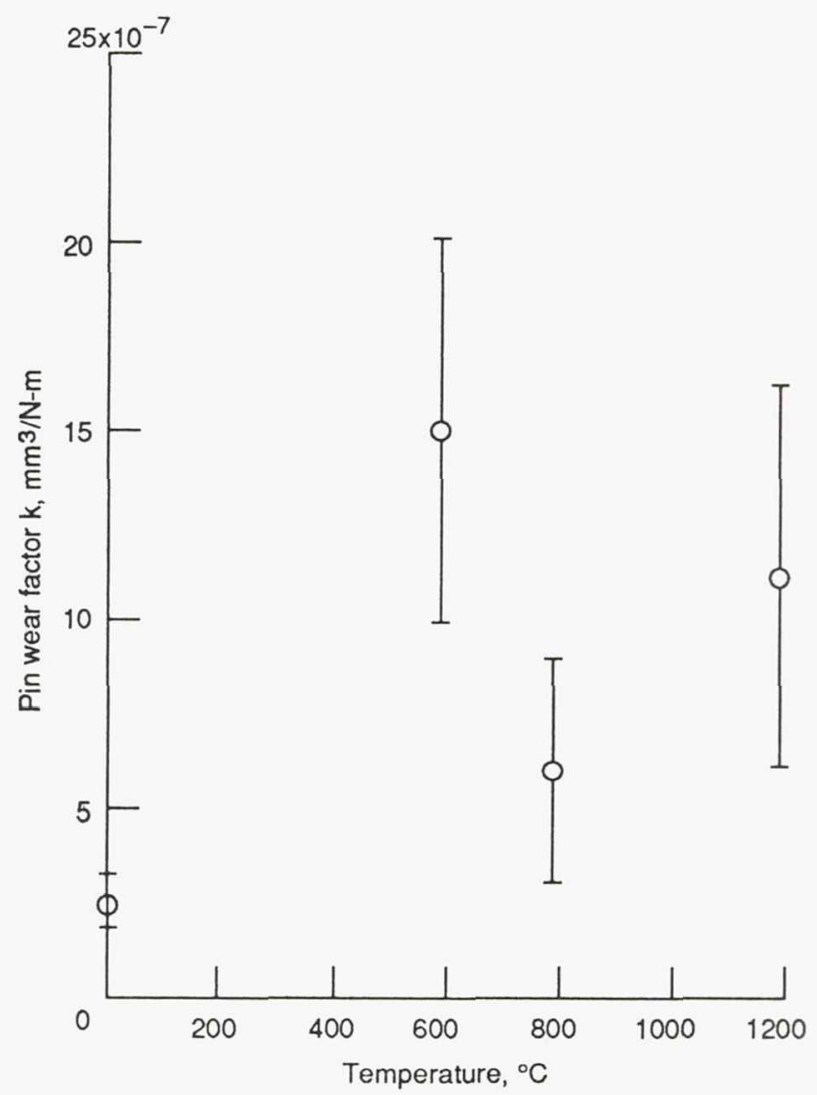

Figure 5.-Pin wear factor, $k$, versus temperature for the $\mathrm{Al}_{2} \mathrm{O}_{3}-\mathrm{SiC}$ composite sliding against itself in air at $2.7 \mathrm{M} / \mathrm{s}, 26 \mathrm{~N}$ load. Error bars represent data scatter band.

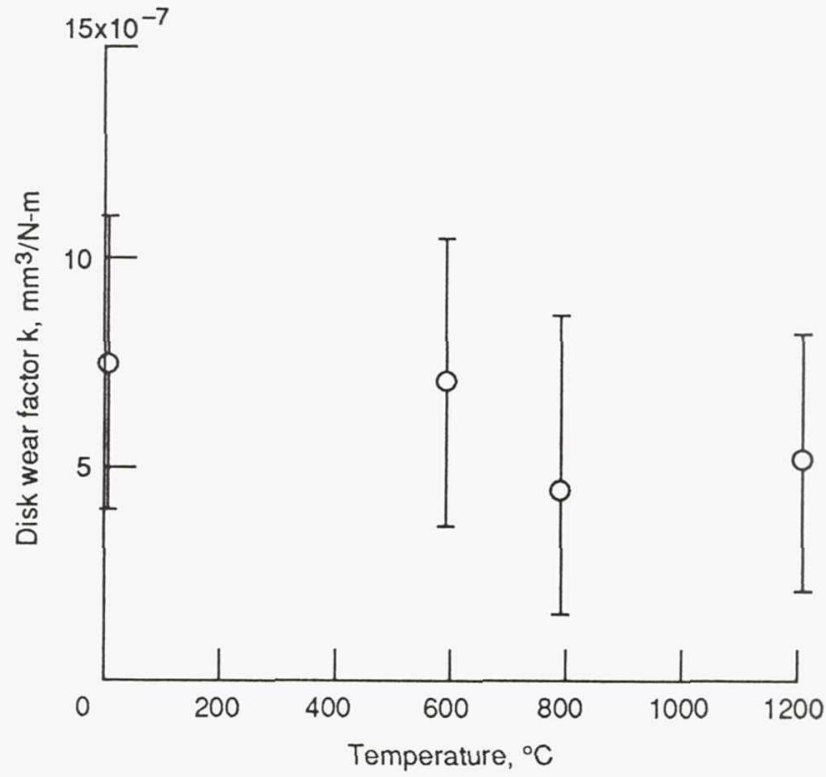

Figure 6.-Disk wear factor, $k$, versus test temperature for the $\mathrm{Al}_{2} \mathrm{O}_{3}-\mathrm{SiC}$ composite sliding against itself in air at $2.7 \mathrm{M} / \mathrm{s}, 26 \mathrm{~N}$ load. Error bars represent data scatter band. 

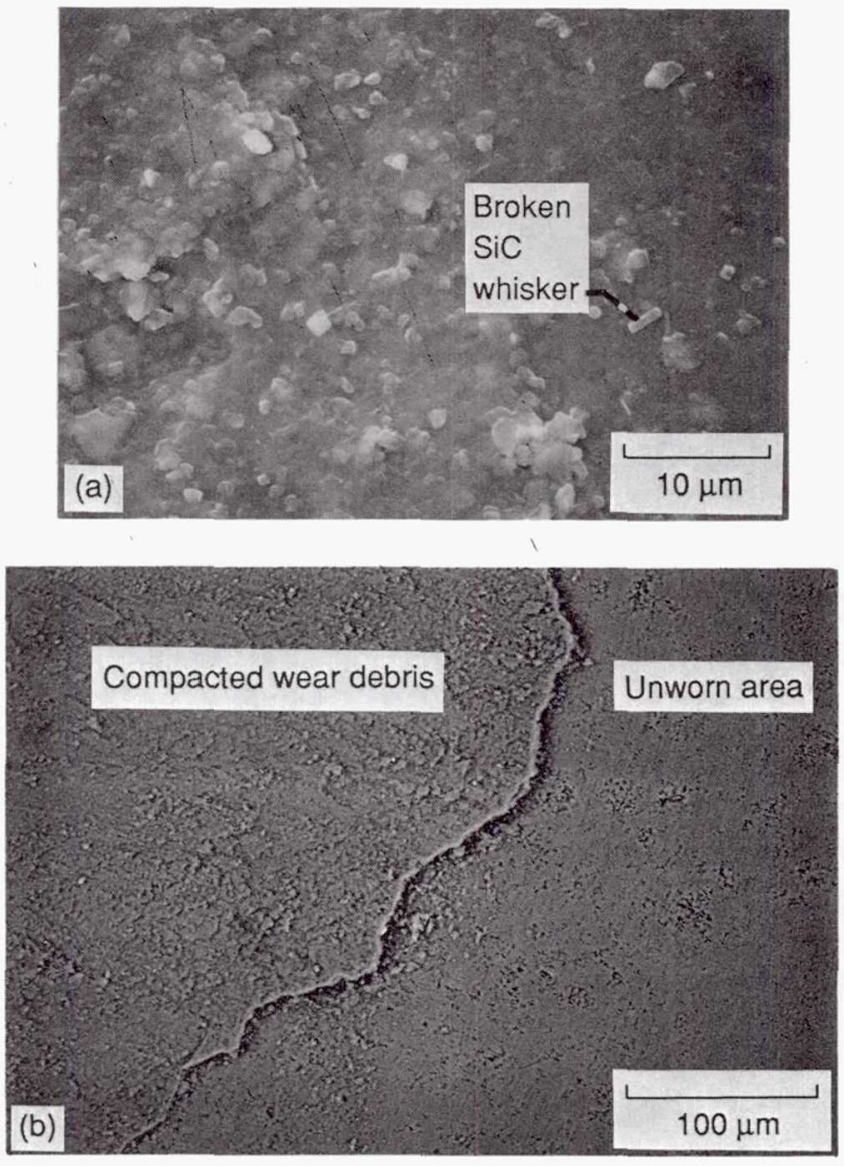

Figure 7.-SEM micrograph of wear scar area from room temperature test. Wear debris is compacted into larger regions.

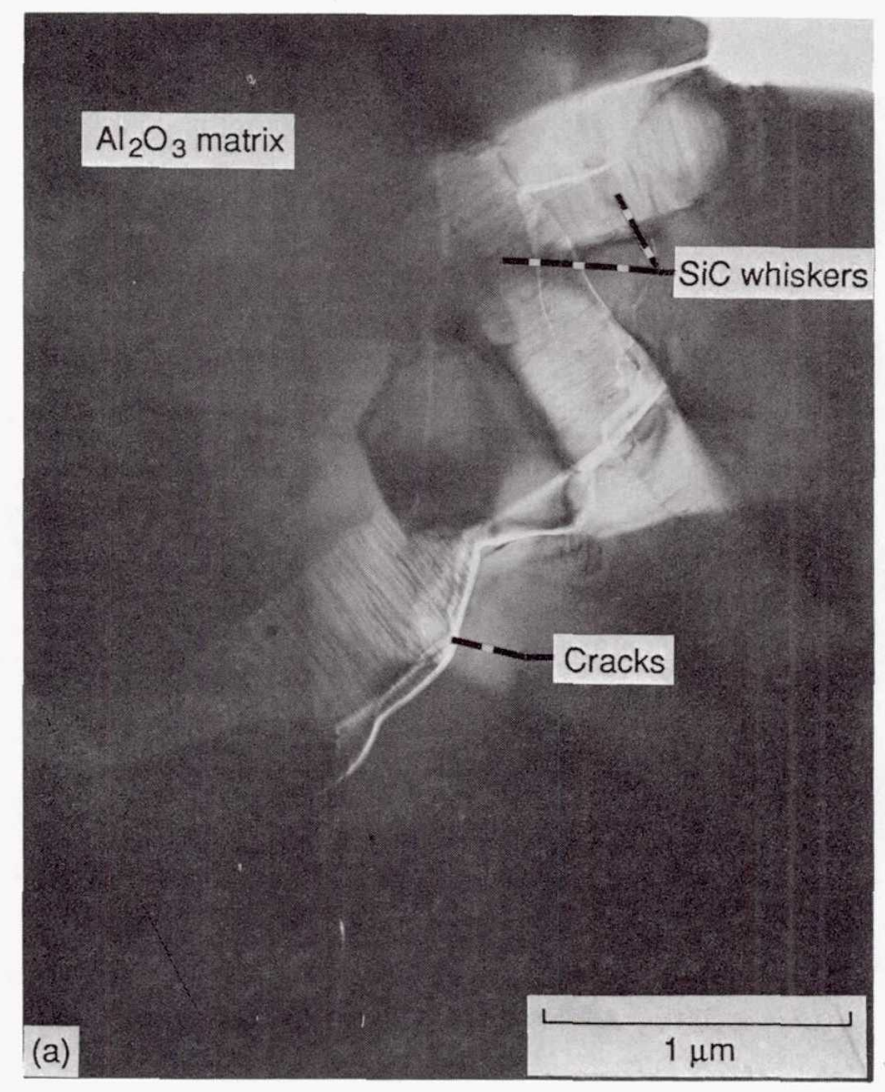

Figure 8.--Room temperature TEM micrographs of pin wear scar showing cracks (8a) and fractured wear debris particles $(8 b, c)$. 

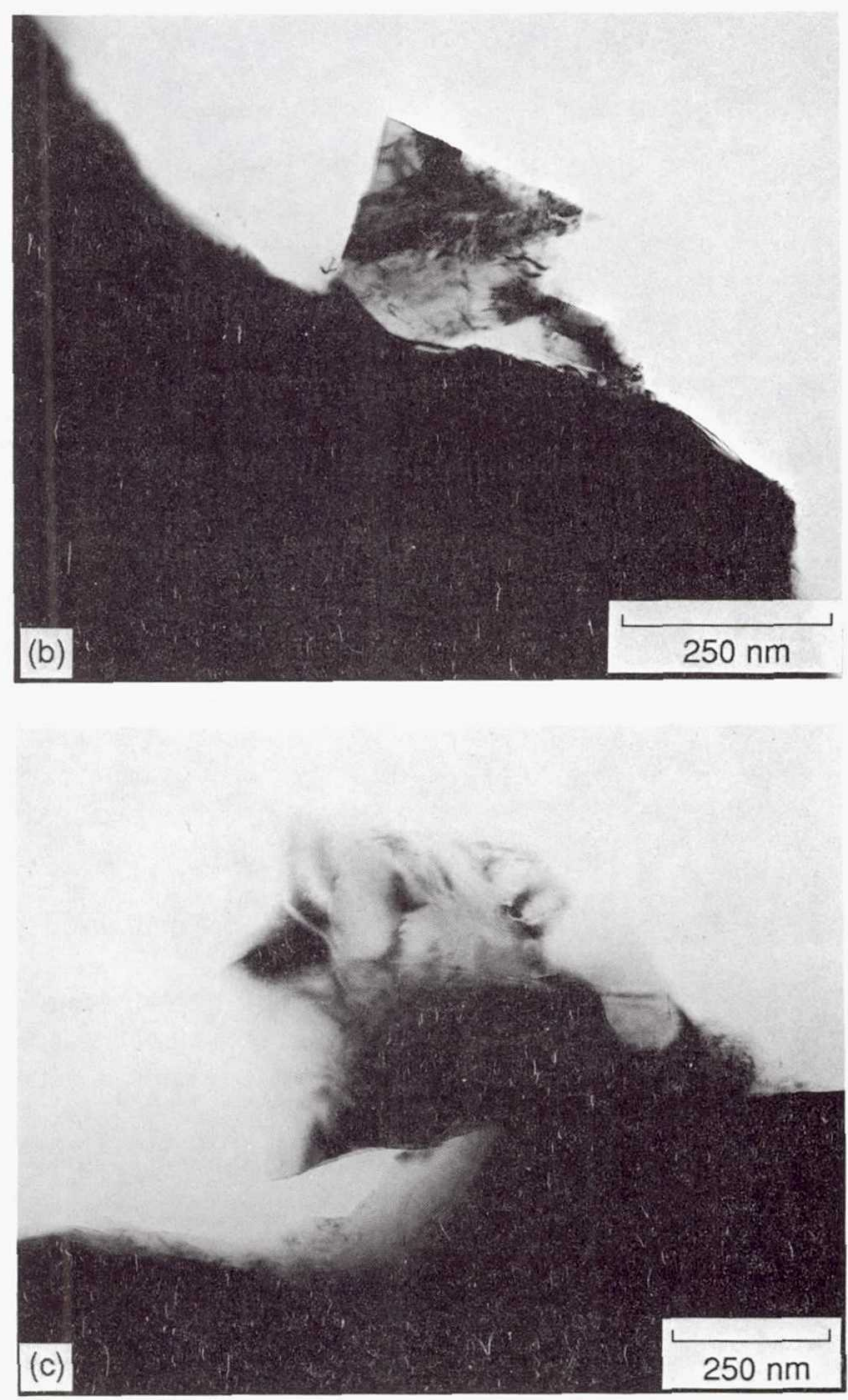

Figure 8.-Concluded
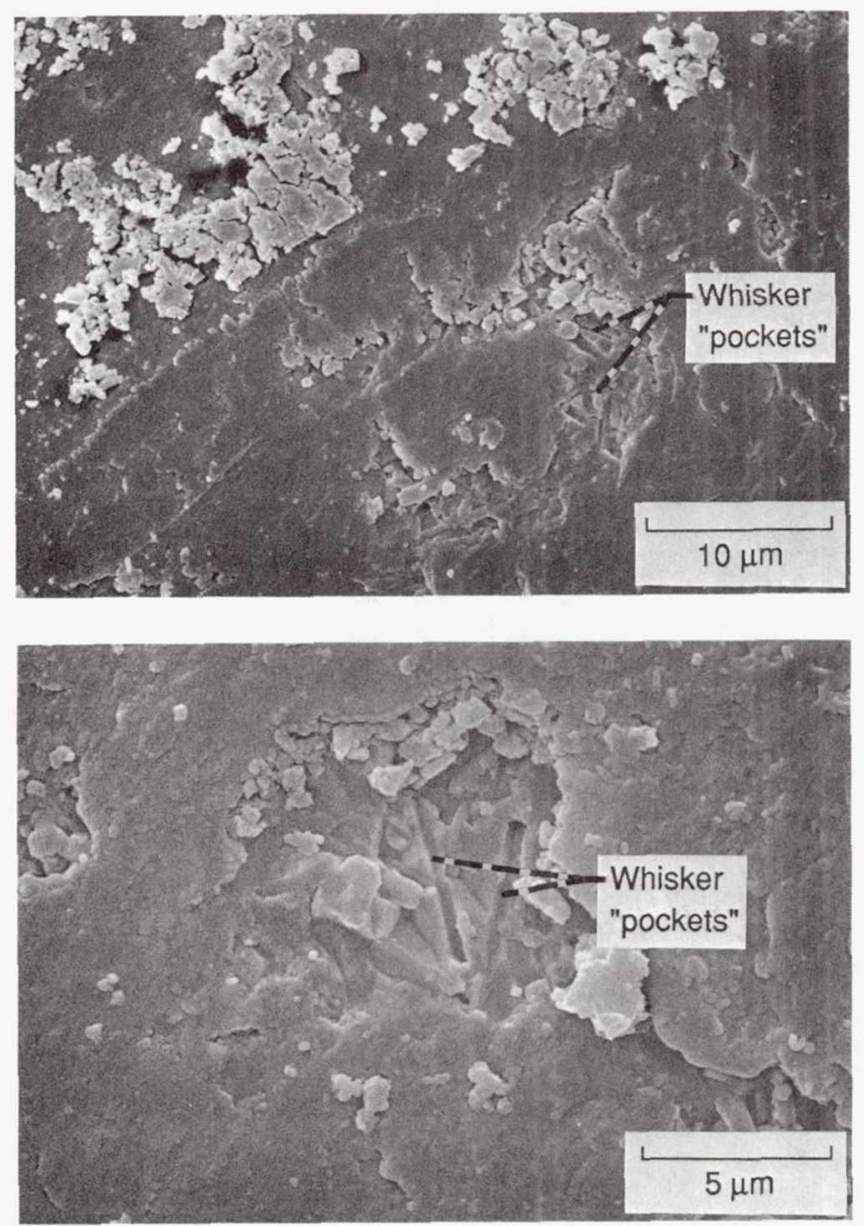

Figure 9.-Whisker pockets left behind by pulled-out whiskers on pin wear surface from $600{ }^{\circ} \mathrm{C}$ test. 

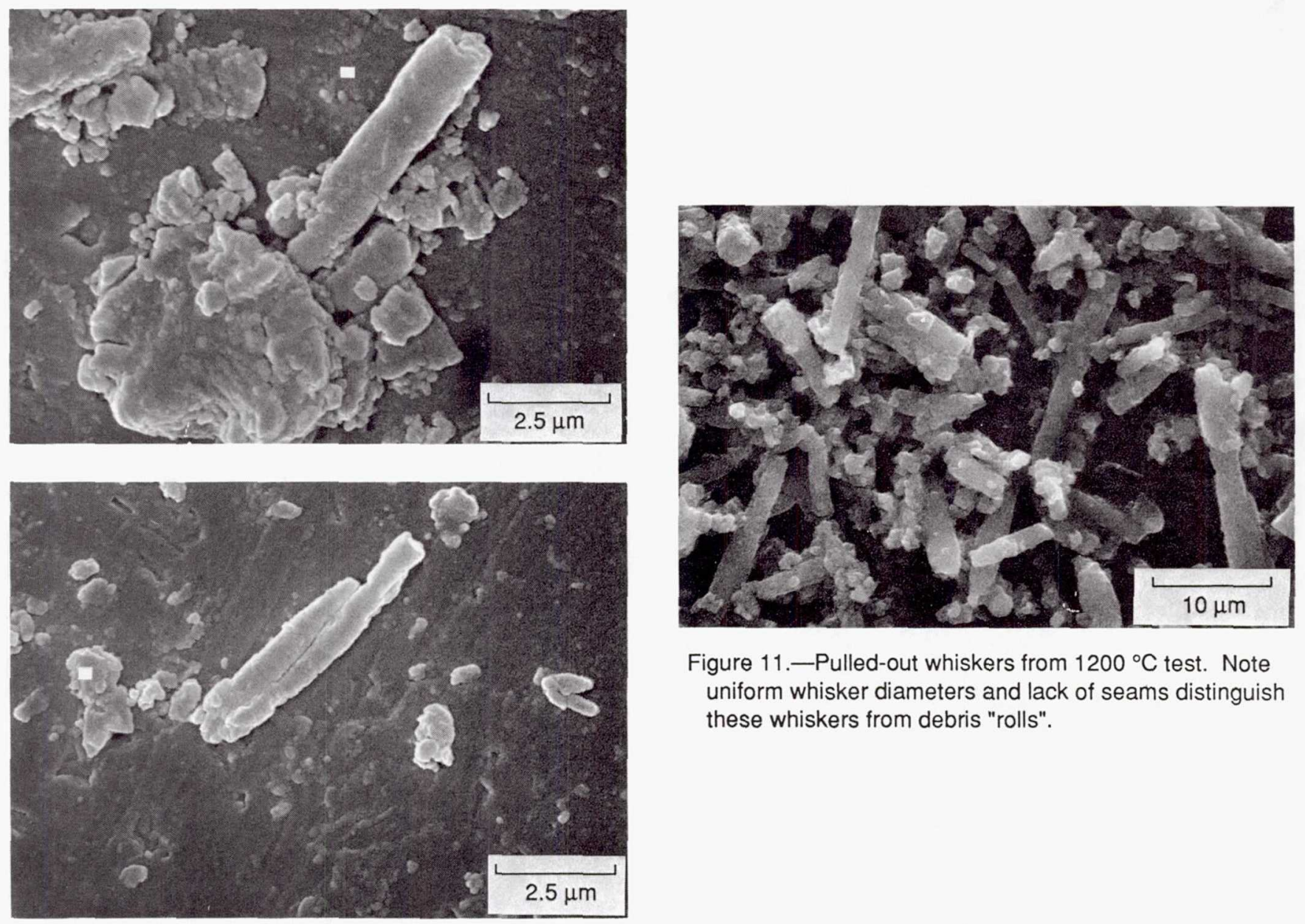

Figure 11.-Pulled-out whiskers from $1200^{\circ} \mathrm{C}$ test. Note uniform whisker diameters and lack of seams distinguish these whiskers from debris "rolls".

Figure 10.-Wear debris "rolls" or needles from $600{ }^{\circ} \mathrm{C}$ test specimens. Note seam along needles and small diameters $(\approx 0.4 \mu \mathrm{m})$ distinguish these from whiskers. 


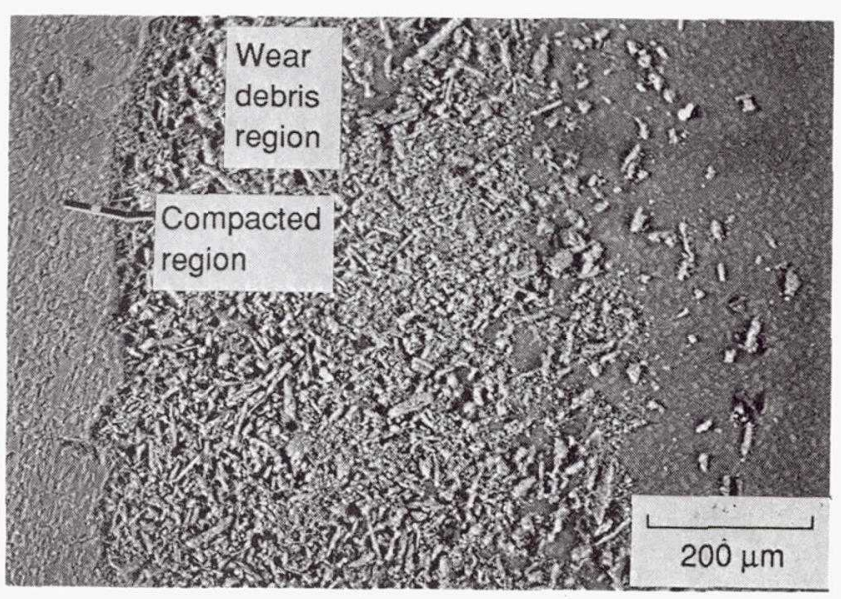

(a) Debris at $105 x$ magnification.

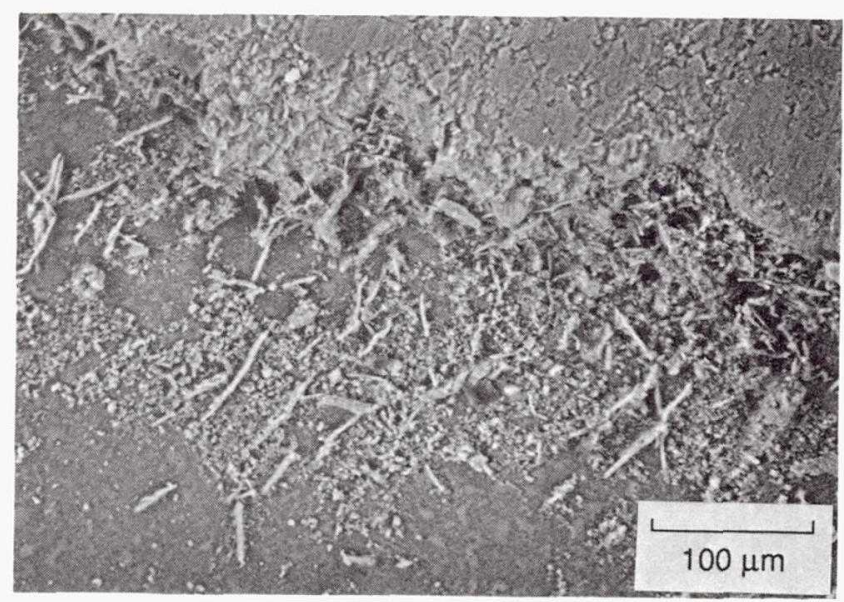

(b) Debris at 200x magnification.

Figure 12.-SEM micrograph of "pulled-out" whiskers outside wear scar from $1200^{\circ} \mathrm{C}$ sample. Note that most of the whiskers are $10-70 \mu \mathrm{m}$ in length.

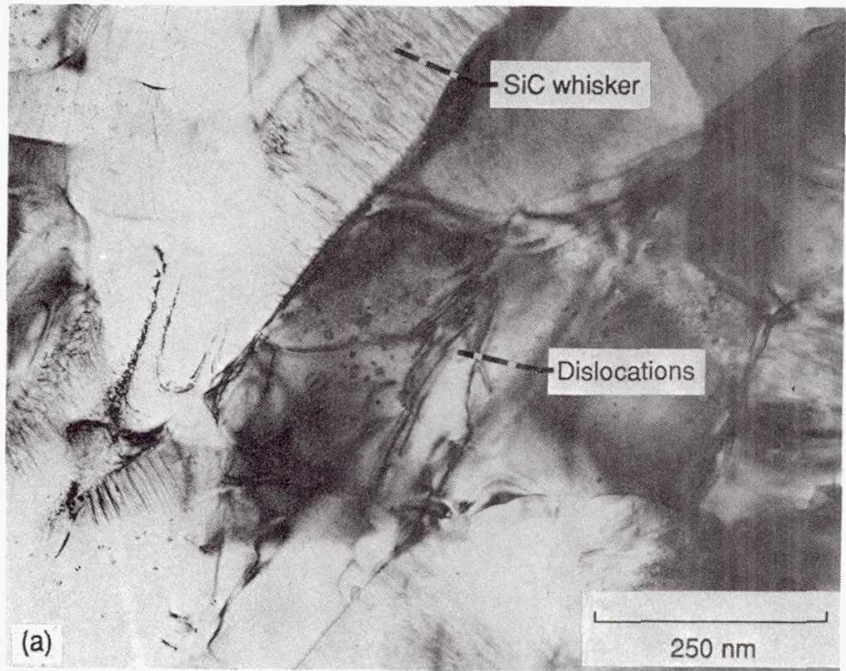

(a) Whiskers shown lengthwise.

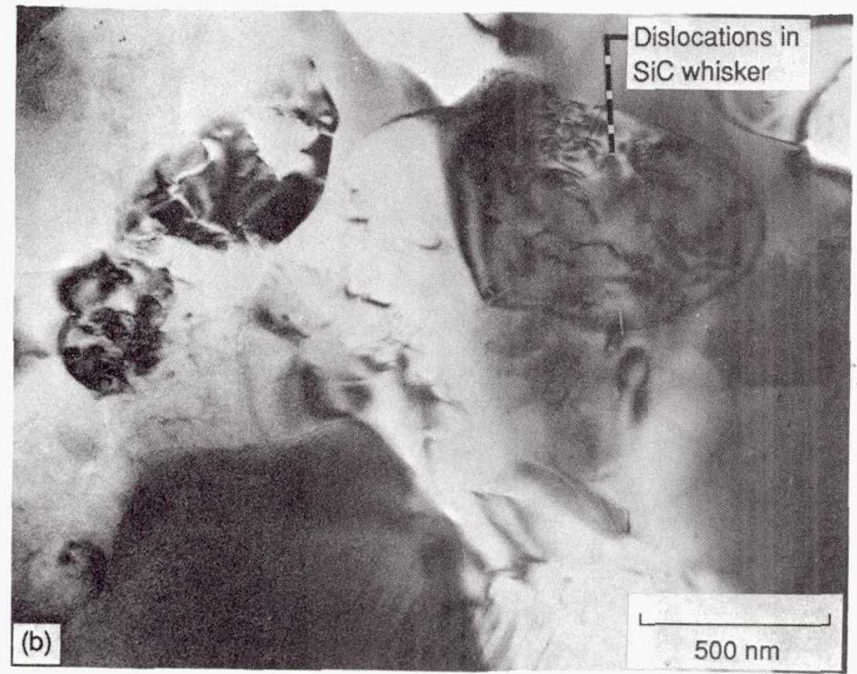

(b) Whiskers shown head on.

Figure 13.-TEM micrograph of pin wear surface from $1200{ }^{\circ} \mathrm{C}$ test sample. Note dislocations induced from sliding. No wear debris detected on wear surface area. 


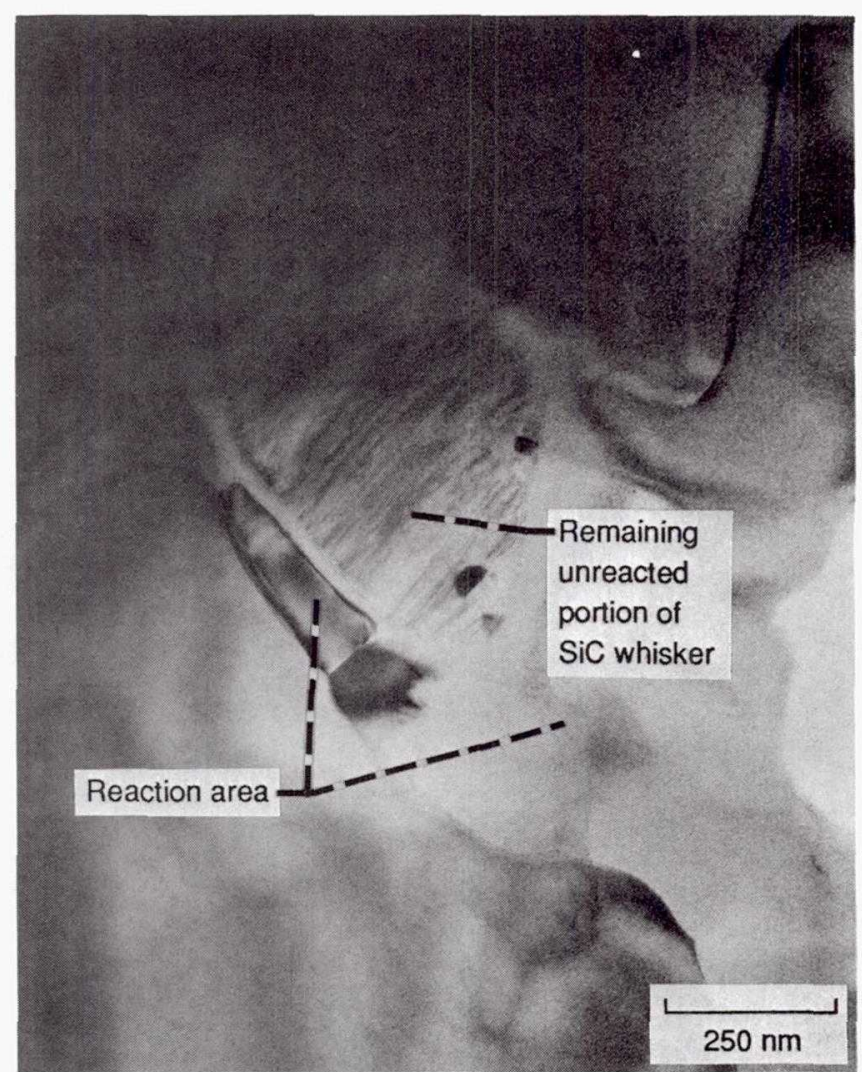

Figure 14.-TEM micrograph of pin wear scar from $1200^{\circ} \mathrm{C}$ test. Figure shows a $\mathrm{SiC}$ whisker which has partially reacted with impurities and matrix. Reaction products may be promoting whisker loosening and pull-out.

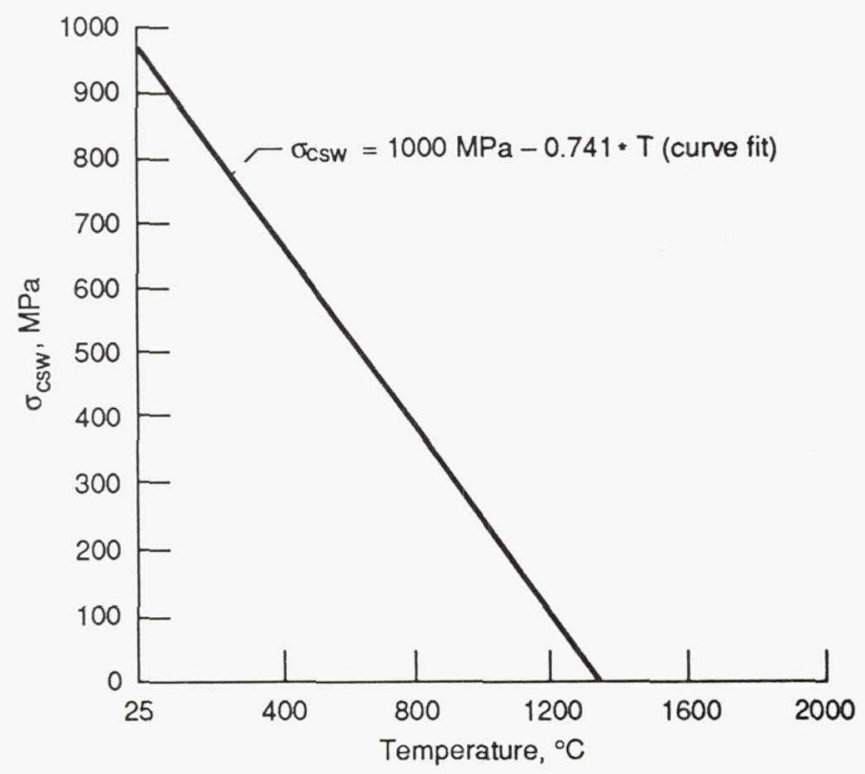

Figure 16.-Variation of maximum residual hoop stresses at whisker surface with temperature. From Ref. 15 for an $18 \%$ by vol. $\mathrm{SiC}-\mathrm{Al}_{2} \mathrm{O}_{3}$ composite.

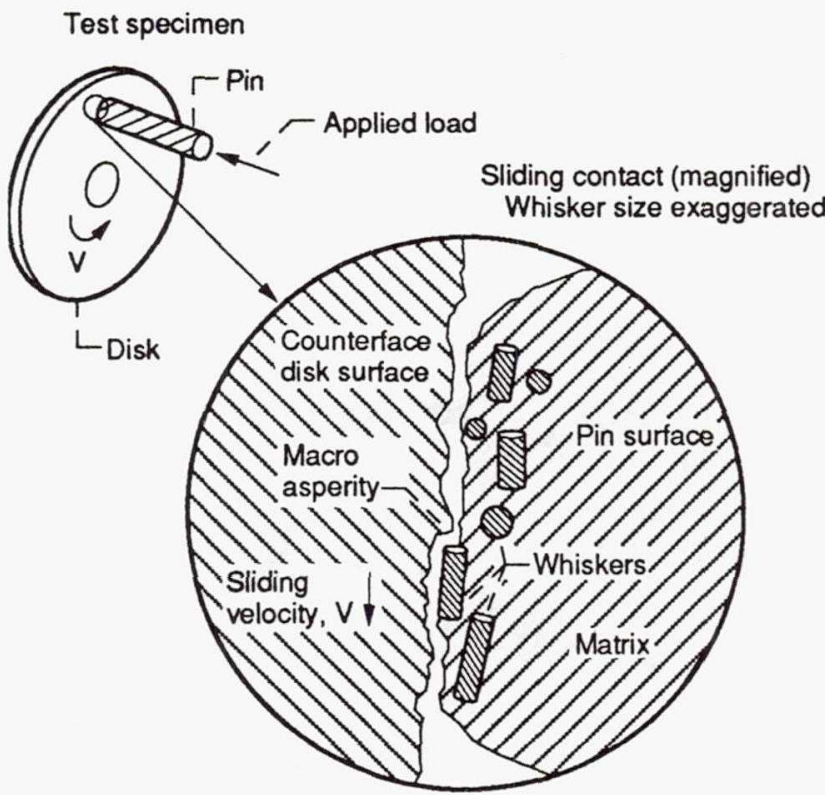

Figure 15.-Pin-on-disk geometry of specimens modeled and an illustration of whisker/asperity interation.

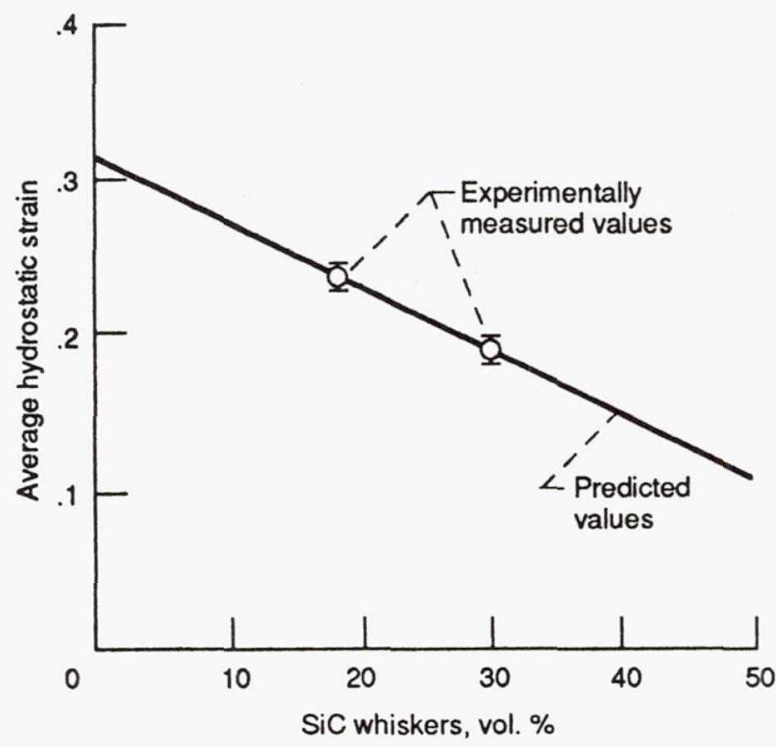

Figure 17.-Compressive strain on $\mathrm{SiC}$ whiskers at room temperature as a function of whisker \% vol from Ref. 15 Error bars represent one standard deviation of measured data. 


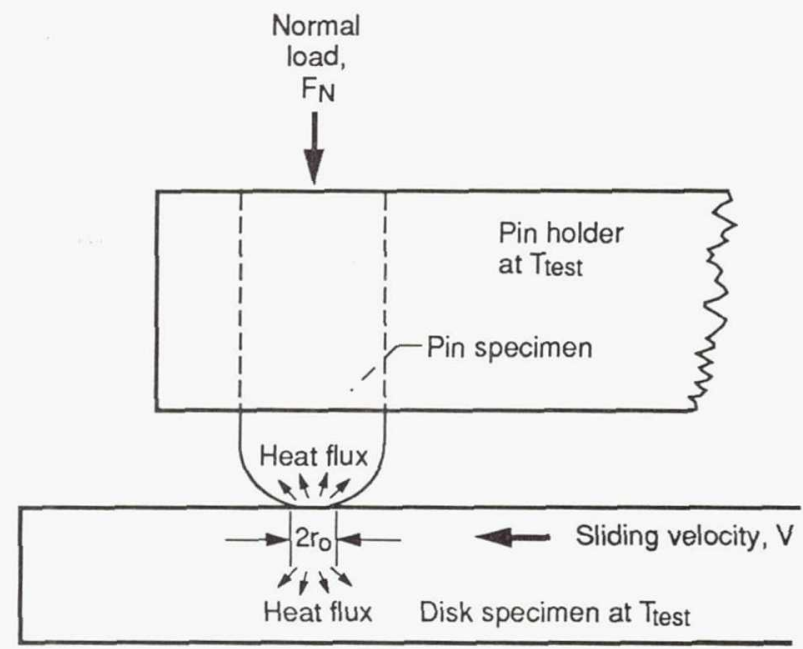

Figure 18.-Sketch of physical situation modelled by heat transfer analysis. Pin and disk specimens have equivatent thermal properties.

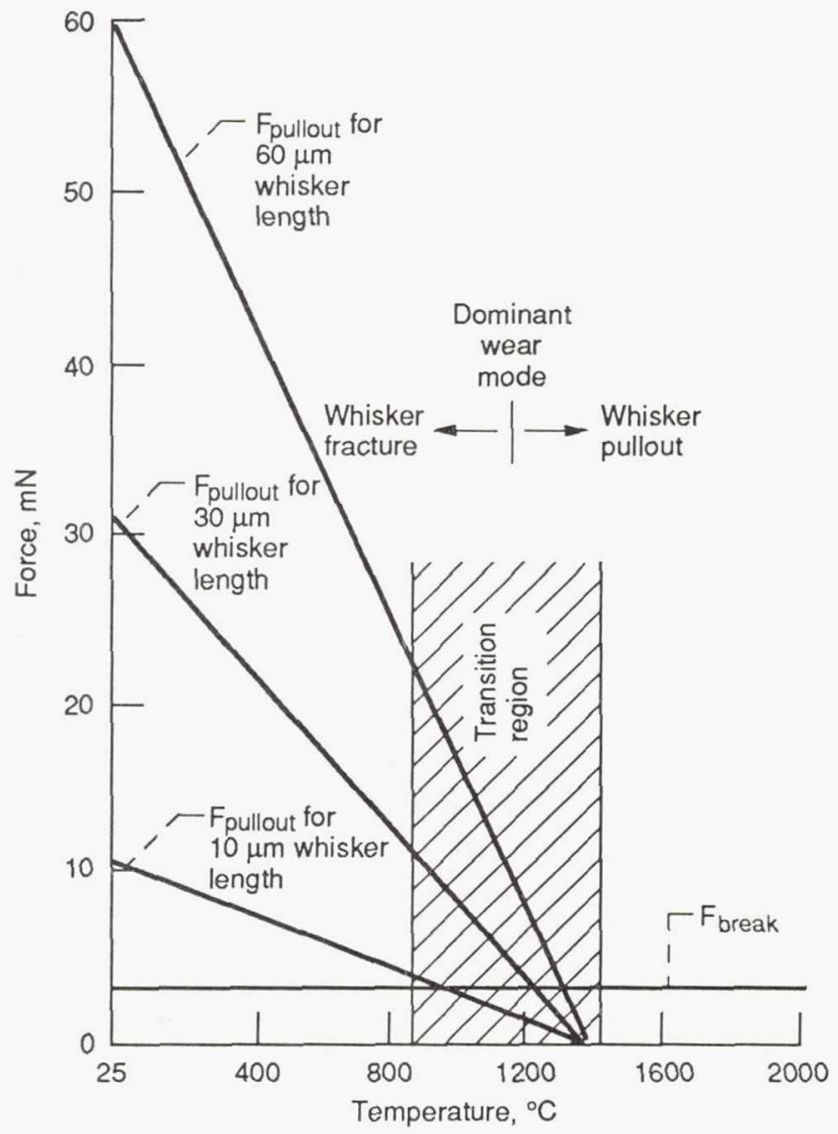

Figure 20.-The effect of average whisker length on Foullout versus temperature. Transition is reduced from 1300 to $950^{\circ} \mathrm{C}$ when whisker length is reduced from 60 to $10 \mu \mathrm{m}$.

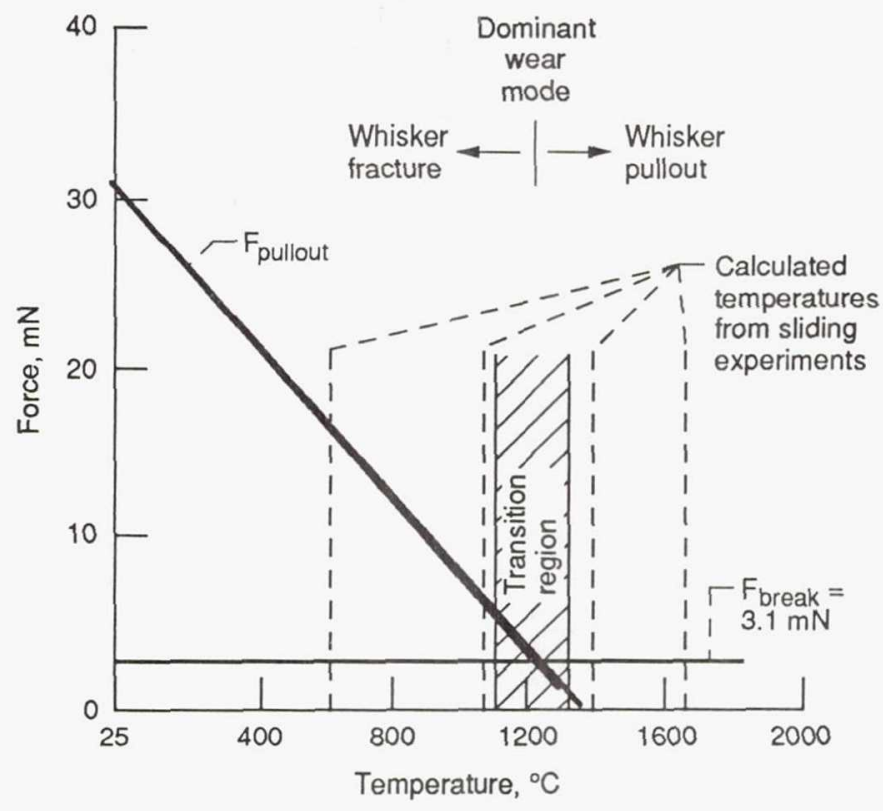

Figure 19.-The variation of whisker fracture force ( $\left.F_{\text {break }}\right)$ and whisker pullout force ( $\left.F_{\text {pullout }}\right)$ versus temperature. Wear mode transition occurs at crossover.

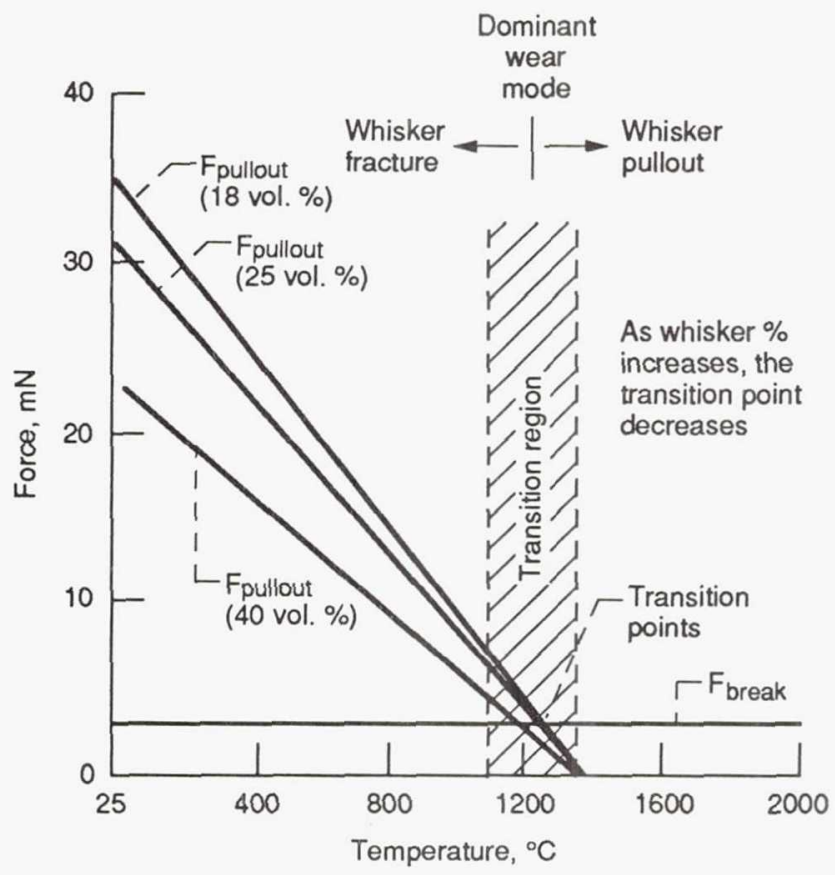

Figure 21.-Variation of transition point as volume percent whisker content changes from 18 to $40 \mathrm{vol} \%$ as a function of temperature. 


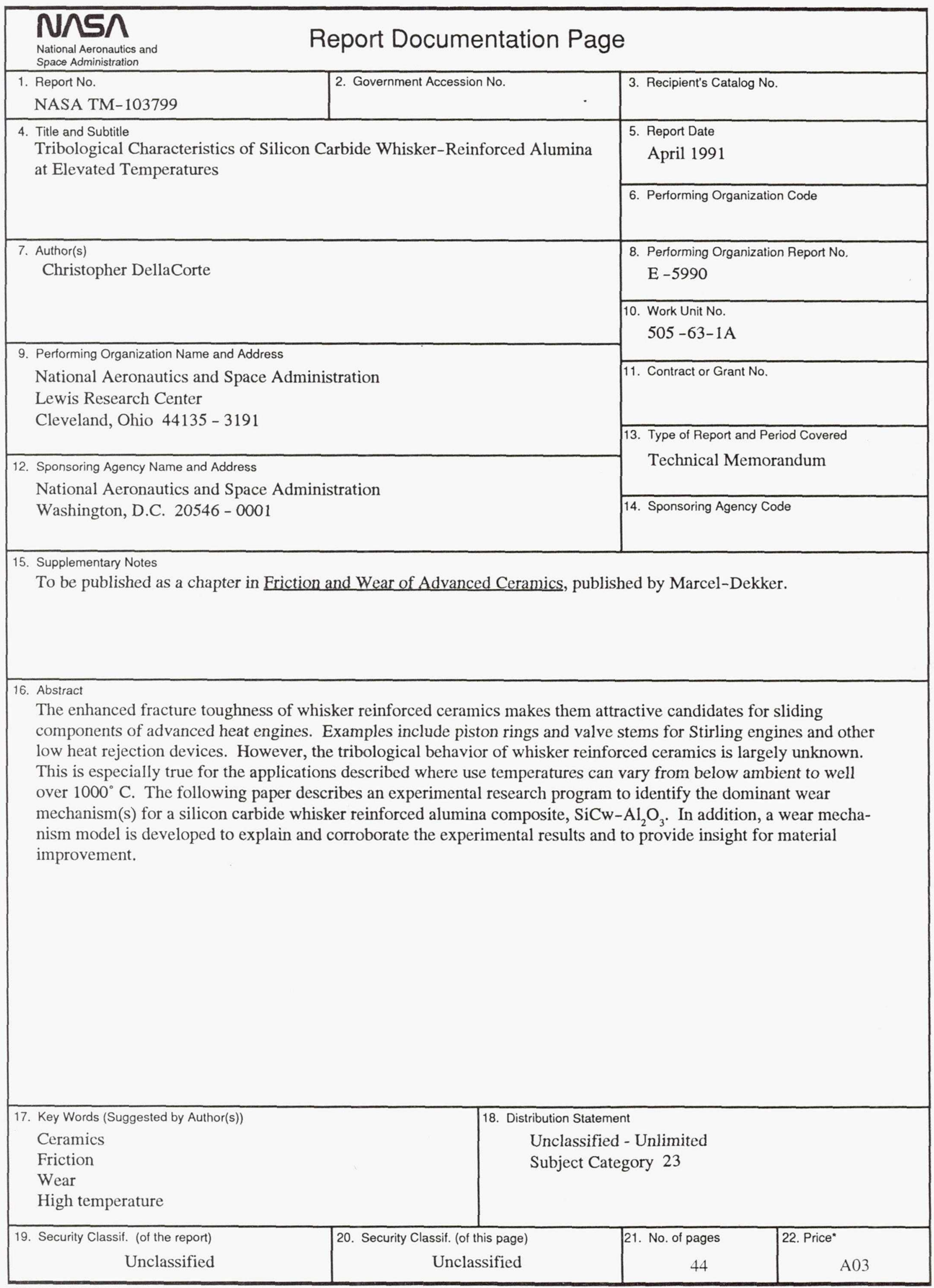

